Article

\title{
Comparative Analysis of Key Factors Encouraging Food Delivery App Adoption Before and During the COVID-19 Pandemic in Thailand
}

\author{
Jankit Chotigo * and Yasuo Kadono
}

check for updates

Citation: Chotigo, J.; Kadono, Y. Comparative Analysis of Key Factors Encouraging Food Delivery App Adoption Before and During the COVID-19 Pandemic in Thailand. Sustainability 2021, 13, 4088.

https://doi.org/10.3390/su13084088

Academic Editor: Amir Mosavi

Received: 9 March 2021

Accepted: 6 April 2021

Published: 7 April 2021

Publisher's Note: MDPI stays neutral with regard to jurisdictional claims in published maps and institutional affiliations.

Copyright: (c) 2021 by the authors. Licensee MDPI, Basel, Switzerland. This article is an open access article distributed under the terms and conditions of the Creative Commons Attribution (CC BY) license (https:/ / creativecommons.org/licenses/by/ $4.0 /)$.
Graduate School of Technology Management, Ritsumeikan University, Osaka 567-8570, Japan; kadono@fc.ritsumei.ac.jp

* Correspondence: gr0401fr@ed.ritsumei.ac.jp; Tel.: +81-80-9360-8166

\begin{abstract}
This study examines and compares the crucial factors encouraging Thai customers to use food delivery apps before and during the COVID-19 pandemic on the basis of the modified conceptual paradigm of Unified Theory of Acceptance and Use of Technology 2 (UTAUT2), including the following external factors: trust, convenience, application quality, and satisfaction. Data were collected from 220 food delivery app users before the pandemic and 250 food delivery app users during the pandemic. The data were analyzed using structural equation modeling based on AMOS 23.0 to test model validity and the study hypotheses. The results indicated that satisfaction was influenced by social influence, trust, convenience, and application quality in both the before- and during-the-COVID-19-pandemic samples. In addition, price value was a significant predictor of satisfaction before the pandemic but not during the pandemic, whereas habit was found to significantly influence satisfaction before the pandemic but was found to negatively influence satisfaction during the pandemic. Additionally, the results of both samples showed that customers with a high level of satisfaction using a food delivery app were more likely to keep using it. The findings may assist marketers in developing appropriate strategies for food delivery app activities.
\end{abstract}

Keywords: food delivery; application quality; trust; convenience; COVID-19; Thailand

\section{Introduction}

Food delivery apps have grown increasingly popular and are revitalizing the food industry, exciting customers who are, in turn, paying more attention to the available options. The shift in customers' food purchasing behavior has spurred the growth of the food delivery business. The growth forecast estimate was $19 \%$ or US $\$ 2.88$ billion at the end of 2020 [1]. Food ordering apps propelled the food delivery business to an annual growth rate of over $10 \%$ from 2014 to 2018 , higher than the restaurant business expansion rate over the same time period, which reached only $3-4 \%$ per year [2].

Of late, digital transformation has brought many changes to the way companies in all sectors do business [3,4]. The food sector has not been exempt from these changes, as evidenced by the increase in the adoption of food delivery apps. At the end of 2018, the number of internet users in Thailand had reached 47.5 million, accounting for $71.5 \%$ of the total population of Thailand, showing great growth in the number of internet users compared to 2013 (26.1 million) [5]. About 57\% of Thai internet users use the internet to purchase products/services, including food items. Therefore, online food delivery services have indeed become more popular, increasing by $15.1 \%$ since 2017 . Online food delivery is the fastest growing service in Thailand [5]. Thai consumers also continue to embrace online shopping and increasingly use their mobile devices to order and buy products/services. Apart from the aforementioned factors contributing to the growth of food delivery services, food delivery apps are also probably among the most important instruments for users with busy lifestyles. Food delivery is also the best option for people who do not want to wait in 
line at a restaurant or who want to have more leisure time with their families. Moreover, Thailand has one of the strongest transport networks and is one of the top three largest food delivery markets in the Southeast Asian region [6,7].

While the COVID-19 outbreak has put full-dine-in restaurants under severe strain, food sales through online platforms have seen a surge in growth rates [8]. The new environment has driven Thai customers to switch to online food delivery services via well-known aggregators, in no small part due to the customers' efforts to avoid exposure to COVID-19. Accordingly, many restaurants have shifted their focus to delivery and takeaways, which have become the key drivers for their sales and revenue growth [5]. This empirical study conducted in Thailand will provide an important contribution to food delivery research.

Considering the aforementioned trends in Thailand and the questions raised by Chotigo and Kadono [9] in their comparative study of the situations before and during COVID-19, the present study aims to identify the key factors that have determined and shaped customer satisfaction with food delivery apps before and during the COVID-19 pandemic. The study thereby aims to contribute to the future development and enhancement of food delivery apps. Studies on food delivery apps are generally limited, and few have been conducted on food delivery in Thailand specifically [10-14].

This study also illustrates the growth prospects of restaurants by leveraging food delivery apps. In addition, it presents customers' perspectives of how such apps can be extremely helpful in satisfying their food cravings. Hence, this study proposes a model that can cover the dimensions related to quality and convenience of use of food delivery apps and customers' trust in and satisfaction with them; this can address Thai customers' concerns regarding such apps based on their experiences of using them.

In summary, the research reported herein attempts to address and explore the following questions:

(1) What are the factors that contributed to the differences in Thai customers' satisfaction with and intention to use food delivery apps before and during the COVID-19 pandemic?

(2) What can food delivery operators do to enhance their customers' acceptance of food delivery apps in Thailand?

The rest of the paper is structured as follows. Section 2 provides an overview of the main themes covered by the existing literature and a summary of food delivery services. Then, we explain the conceptual model and the research hypotheses. Section 3 presents the method that was used in the study, and Section 4 provides the most relevant findings and results from the analysis. Section 5 discusses the theoretical and practical implications of the research. Finally, Section 6 presents the conclusions, research limitations, and suggestions for future research.

\section{Literature Review and Hypotheses}

\subsection{Food Delivery Service}

A food delivery app is an innovative and convenient channel, downloadable in the form of a smartphone mobile application, that allows smartphone users to order and pay for food from a wide array of restaurants; the food is typically delivered to the customers' doorsteps without any physical interaction with restaurant staff [14]. Food delivery apps are becoming increasingly popular in Thailand, without any sign that such popularity will decline anytime soon because they offer consumers greater convenience, flexibility, and choices. Currently, diners tend to eat at home or their workplace more often than in walk-in or dine-in restaurants. Moreover, they tend to pay more attention to healthy eating and sustainable consumption $[15,16]$. Food delivery apps act as a blessing to this behavior of consumers, enabling them to consume their choice of diet with accurate nutritional facts and the promotion of sustainable consumption. The impact of this digital disruption is significant because restaurants are seeing a reduction in their number of walk-in or dine-in customers. 
KResearch [2] found that $63 \%$ of the survey's participants believed that the advent of food delivery apps transformed their food consumption behavior. Diners are increasingly ordering food through online platforms and eating out less in restaurants. The rapid increase in food delivery options and food delivery apps has also increased the opportunities for different players in the restaurant business, including street food and local cuisine providers, to generate more income and reach out to new groups of customers.

The COVID-19 pandemic has driven a surge in demand for food delivery services due to social-distancing protocol and people's fear of infection. As a result, 2020 seems to have marked the start of the golden era of food delivery, particularly for the main four aggregators: GrabFood, GET, Line Man, and Foodpanda. The pandemic has also fuelled the rise of new players. For instance, Robinhood has been promoted as a "Thai food delivery service for Thai people," which aims "to help society" by providing lower fees and faster payouts through online banking payment systems. Thus, competition in the increasingly lucrative food delivery sector is showing no signs of cooling down [17].

Over 20,000 local food shops and restaurants launched online food delivery services in the first quarter of the current year (2020), and these businesses grew by $150 \%$ compared to the same period last year. Many Thai operators are following a new business strategy that includes keeping prices down by not collecting service fees from restaurants, adding extra features to their apps, and even giving customers a chance to compare prices. KResearch [2] has estimated that the food delivery industry will grow by $17 \%$ in the second half of this year compared to the same period last year. This number may grow exponentially by $78-84 \%$ if a new wave of COVID-19 infections emerges [18].

\subsection{Unified Theory of Acceptance and Use of Technology 2}

Many prior studies have explored and investigated the key drivers of technology adoption intention by drawing on prominent models such as TAM [12,19-21]; Unified Theory of Acceptance and Use of Technology 2 (UTAUT2) [22]; an extension of UTAUT2 that incorporates security, privacy, and trust [23]; an extension of UTAUT2 that incorporates perceived value [24]; an extension of UTAUT2 that incorporates trust [25]; an extension of UTAUT2 that incorporates risk [26]; an integrated TAM [27,28]; UTAUT [29]; the information systems (ISs) success model [30]. Researchers must exercise caution in selecting which model they will use when examining the factors predicting customer intention to adopt a technology. The present study adopted UTAUT2 (shown in Figure 1), as suggested by Venkatesh et al. [31], to determine Thai customers' perspectives on technology adoption intention. However, the original UTAUT2 model was modified by not considering the role of performance expectancy, effort expectancy, hedonic motivation, and facilitating conditions, which do not exist in the context of food delivery apps. Therefore, convenience [12,32,33]; trust $[20,25,33]$; quality $[21,30,33,34]$; and satisfaction $[14,27,30,32]$ were added to complete the model and to broaden the theory and practice. In addition, many empirical studies have confirmed that these external factors are crucial to influencing customer engagement and technology adoption intention. Furthermore, these external factors have not been fully considered by prior studies, and few studies have modified UTAUT2 in the context of food delivery apps in Thailand. 


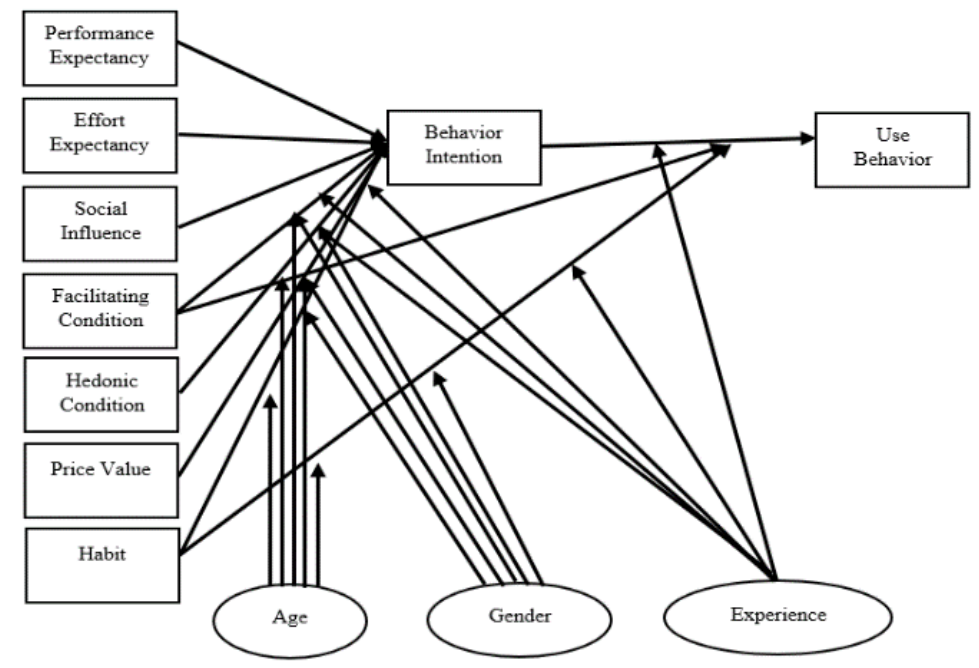

Figure 1. The Unified Theory of Acceptance and Use of Technology 2 (UTAUT2) model.

\subsubsection{Price Value}

According to Venkatesh et al. [31], the UTAUT2 model incorporates a price value construct to determine the role of financial issues in customer technology use, defined as customers' cognitive trade-offs between the perceived benefits of an app and the monetary cost of using it. Customers are likely to consider how much they are willing to pay to satisfy their needs or receive goods and services. Adjusting the price (including setting the price) has a profound impact on marketing strategy and will often affect customer demand and satisfaction. Based on prior studies, price value is one of the main factors contributing to customers' intention to use a new technology [24,25,31]. Moreover, increasing the perceived benefits or reducing the perceived costs of using a food delivery app can make customers more likely to be satisfied with it. Iyer et al. [35] revealed that perceived value plays a role in determining customer satisfaction with a retailer app. Thus, the hypothesis below is proposed.

Hypothesis 1 (H1): Price value (PV) has significantly and positively affected customer satisfaction toward food delivery app adoption before and during the COVID-19 pandemic.

\subsubsection{Social Influence}

Social influence is the main predictor of technology acceptance and appears in both the UTAUT and UTAUT2 models. Venkatesh et al. [36] defined social influence as "the extent to which an individual perceives the degree of approval of a certain behavior by important referents (p.159)". As food delivery services and apps are new in Thailand, as of this writing, customers are still not fully familiar with using such apps. Thus, opinion leaders (family, friends, celebrities) play an important role in customers' acquisition of more information regarding their use. Opinion leaders also influence the use of certain things for the first time in one's life, particularly for those who are in the early stage of adoption of a new technology. Several studies have proven that social influence positively influences customers' intentions, and this finding is supported in various fields, such as mobile diet apps [15], mobile commerce [22], and near-field-communication mobile payments [37]. A relationship between social influence and customer satisfaction was shown in the studies of Hsiao et al. [38] and Gallarza and Gil Saura [39], who found that if customers have a high level of trust in their group or a person, they will be easily influenced by such group or person to act. The study conducted by Chotigo and Kadono [9] on food delivery apps during the COVID-19 pandemic suggested that creating appropriate campaigns or activities through social network tools will help convince more customers to adopt a food delivery app and will enhance the customers' experiences with the app. The study also showed 
that social influence plays a significant role in shaping customer satisfaction. Hence, the hypothesis below is proposed.

Hypothesis 2 (H2): Social influence (SI) has significantly and positively affected customer satisfaction toward food delivery app adoption before and during the COVID-19 pandemic.

\subsubsection{Habit}

Venkatesh et al. [31] also added habit to the UTAUT2 model, where a habit is an automatic behavior formed through learning or individual experience over time. In that study, when the customers found that the technology provided benefits and pleasing outcomes, they tended to use it more often, leading to habit creation. Prior studies have widely accepted the hidden role of habit in motivating existing customers to continue to use a technology and its influential role in convincing people close to such customers to adopt the technology [14,22,26,31]. Habit also influences customer satisfaction, as one can isolate the difference between an actual craving and essential or pleasing factors, thus establishing the individual's habit [40]. Moreover, during the current COVID-19 pandemic in Thailand, habit has been observed to predict customer satisfaction with the use of food delivery apps [9]. Thus, the hypothesis below is proposed.

Hypothesis 3 (H3): Habit (HT) has significantly and positively affected customer satisfaction toward food delivery app adoption before and during the COVID-19 pandemic.

\subsubsection{Trust}

In the business field, trust is essential because it provides customers with a sense of safety. Service providers need to be able to create truthful connections with their customers to provide the basis for a good consumer-brand relationship and long-term success. Creating valuable content or campaigning can motivate customers to use a product or service and establish long-term relationships with them. To create trust between a brand and a customer, service providers should refrain from making any false promises that they cannot meet and focus on the continuous development of their products or services to improve their business reputation. We defined trust as the consumers' belief that a chosen app will bring the best benefit to them [41]. Trust was found to be important in predicting customer adoption of a technology in [23,25,41-44]; in those studies, it was stated that gaining the customers' trust is the key success factor behind the customers' willingness to patronize a certain product or service; trust enhances customer loyalty to the brand. Therefore, food delivery service providers should focus on building customer trust to retain customer interest in their brand. Customers expect the truth and will continue to trust service providers even if some product or service limitations are observed, provided they are not given false promises.

Meeting customer expectations can create a favorable feeling. A study on food delivery apps during the COVID-19 pandemic revealed that the presence of professional customer service staff to answer customer questions and handle customer problems could shape customer trust and satisfaction [9]. Moreover, the relationship between trust and satisfaction was examined and verified in [9,45-48]. Thus, the hypothesis below is proposed.

Hypothesis 4 (H4): Trust (T) has significantly and positively affected customer satisfaction toward food delivery app adoption before and during the COVID-19 pandemic.

\subsubsection{Convenience}

In simple terms, convenience is experienced in terms of time and effort. Copeland [49] defines convenience as the total time and effort an individual spends to avail of a service or purchase a product. In the context of food delivery apps, convenience may be defined as the time and energy that a customer uses to avail of online food services. As can be seen in the existing literature, convenience has been found to play a crucial role in forming 
customer preference for technology [50-52]. Therefore, food delivery service providers should be well aware of the amount of time that customers spend using their app and the amount of effort that they exert doing so. If food delivery service providers can meet the customers' expectations of them, the customers will become aware of the benefits of their services and will be satisfied, adding value to the businesses. The key assertion is that the perceived convenience of use of food delivery apps depends on their actual convenience of use. Customers can easily order food and get it delivered with minimum effort through food delivery apps, while visiting a restaurant requires time, effort, and energy. To maximize user convenience of their services, food service providers should focus on service agility, accessibility, and availability with time and location flexibility [32]. Furthermore, providing easy access to an app using social logins (social media sign-on) and supporting multiple payment options can enhance the users' experience of the app and the perceived level of convenience of using it. A recent study on food delivery apps during the COVID-19 pandemic showed a significant relationship between convenience of use and customer satisfaction with food delivery apps [9]. Thus, the hypothesis below is proposed.

Hypothesis $\mathbf{5}$ (H5): Convenience (C) has significantly and positively affected customer satisfaction toward food delivery app adoption before and during the COVID-19 pandemic.

\subsubsection{Application Quality}

Application quality is the top concern regarding the customers' use of a technology and is critical to customer satisfaction. An increase in technology and a competitive environment requires new actions. Companies that do not consider and meet the demanded quality standards of their products and services have no chance of survival in the market. Companies must persevere to understand their customers' requirements and must focus on exceeding their customers' expectations. Therefore, quality is crucial for business success and future development. In the food delivery app context, application quality can be defined as a multidimensional interface stimulating negative or positive responses to the use of the food delivery app [21]. Delone and McLean [53] proposed an updated model to assess the success of ISs, as shown in Figure 2. The ISs success model suggests that measures of quality perception should include three aspects: system quality, information quality, and service quality. A simple design, with high efficiency and live-chat functionality, has been found to play an important role in improving people's experiences of using food delivery apps during the COVID-19 pandemic [9]. Prior findings on the ISs success model in various fields have shown that perceived quality affects customer satisfaction $[9,34,54,55]$. Thus, the hypothesis below is proposed.

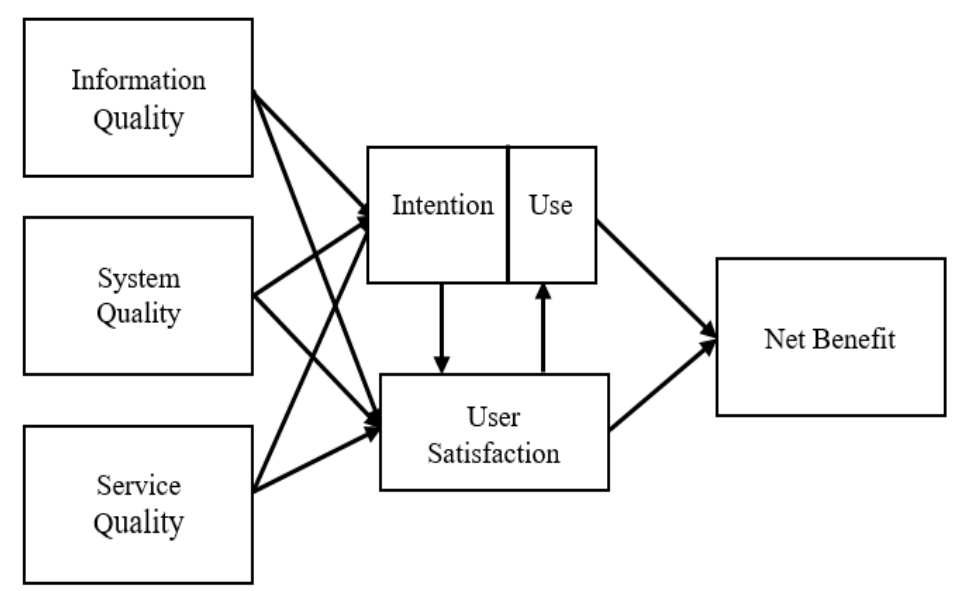

Figure 2. Information systems (ISs) success model. 
Hypothesis 6 (H6): Application quality $(A Q)$ has significantly and positively affected customer satisfaction toward food delivery app adoption before and during the COVID-19 pandemic.

\subsubsection{Satisfaction}

The competition for customers is stronger than ever before in the food delivery market due to overcrowding. Just attracting new customers is not enough to guarantee business success. Ensuring customer satisfaction and keeping existing customers satisfied have become the most critical business goals to increase revenue and expand the customer base. Satisfaction is a cumulative feeling developed after multiple uses of an app and after multiple interactions with service providers. It is evident that the more customers are satisfied, the more they are likely to use the product or service again in the future. Satisfied customers are hidden treasures, and keeping them fully satisfied and happy is the key to retaining them as regular customers. In the food delivery app context, satisfaction is defined as the user's pleasure from using a food delivery app [9]. During the current COVID-19 pandemic, providing superior services and exceeding customer expectations have improved customer experience (satisfaction) when using food delivery apps [9]. Several studies have shown evidence of a positive correlation between customer satisfaction and intention to use a technology $[9,14,28,43,56]$. Clearly, satisfaction plays a vital and significant role in determining the revenue that a customer generates for a business establishment. This study has adopted satisfaction rather than the technology acceptance model's (TAM) attitude construct proposed by Davis [57], as shown in Figure 3. Thus, the hypothesis below is proposed.

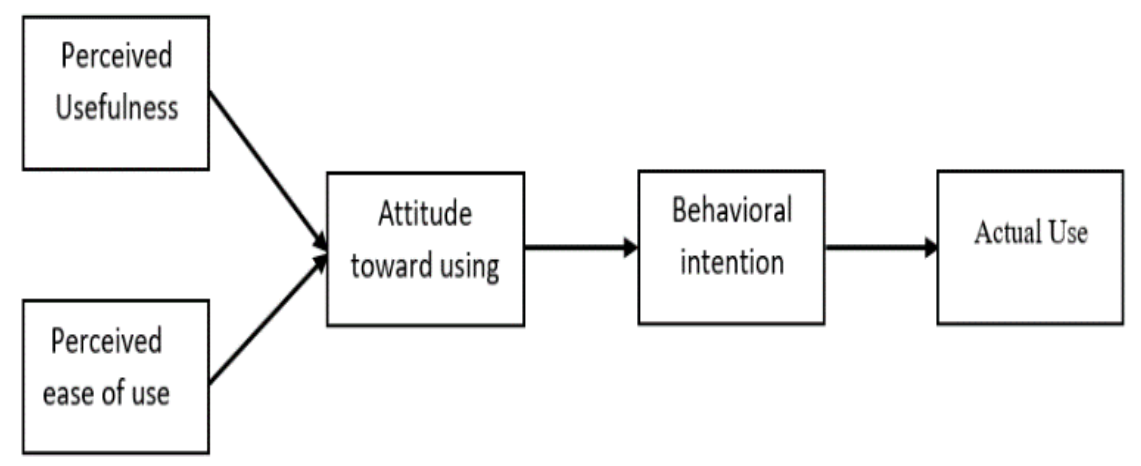

Figure 3. Technology acceptance model (TAM).

Hypothesis 7 (H7): Satisfaction (SAT) has significantly and positively affected intention to use food delivery apps before and during the COVID-19 pandemic.

\section{Methodology}

\subsection{Structural Model}

This study aims to examine and explore the factors shaping customer satisfaction toward food delivery app adoption before and during the COVID-19 pandemic in Thailand. The related prior studies were carefully considered in order to build an appropriate model for identifying the main predictors of customer satisfaction toward creating customer intention to use a food delivery app. The related prior studies attempted to discover the key factors that could convince more customers to adopt a food delivery app by forming conceptual models and extending the most prominent relevant theory. For instance, the extended UTAUT model, with the moderating effect of personal innovativeness [15], was found to be insignificant. Some studies attempted to extend UTAUT2 by incorporating information quality [58], perceived credibility [59], and e-satisfaction [14] thereto. Wang et al. [30] attempted to modify the ISs success model, and Roh and Park [12] attempted to modify TAM. Cho et al. [13] researched the effect of food delivery app quality on userperceived value and found that convenience, design, trust, and food choice shaped the 
value of the app, as perceived by the customer, and influenced customer attitude and app use intention.

Many researchers have also explored the key factors influencing customers' intention to adopt a technology, such as customer experience [32], information technology [3], online social media [27], mobile instant messaging [56], mobile commerce [21,24,60], and mobile banking $[23,25,26]$.

This study adopts UTAUT2, modifying and including external factors to it to propose a conceptual model that would fit the food delivery app context. The modification of the model is presented in the following paragraphs.

First, performance expectancy, effort expectancy, hedonic motivation, and facilitating conditions (constructs from the original model) were excluded, and three other constructs associated with food delivery apps were included, as shown in Figure 4. Consumers use food delivery apps to save time and energy and to increase their leisure or relaxation time. Hence, performance expectancy is not required. In addition, given the overlap between performance expectancy and perceived usefulness of the app, some study results have revealed that the impact of performance expectancy on adoption intention can be uncertain as the relevant findings are mixed $[14,61]$. Furthermore, the food delivery app user's journey begins at the sign-up and goes on until the end of the food delivery process. Therefore, it is necessary to cut superfluous information to make the app simpler and easier to use. Hence, effort expectancy does not exist. Alalwan [14] revealed that effort expectancy does not affect e-satisfaction and adoption intention as people no longer tend to wait for food at a restaurant but tend to look for a more convenient way to get their favorite food items. In addition, users use food delivery apps for their benefit more than for fun or entertainment. Thus, hedonic motivation was excluded from this research model. Prior studies on mobile commerce failed to confirm the role of hedonic motivation [60,62]. Experienced users are less likely to be influenced by facilitating conditions due to familiarity, as food delivery apps are quite common and omnipresent. Recent studies have also found no evidentiary support for the influence of facilitating conditions on adoption intention [15,24].

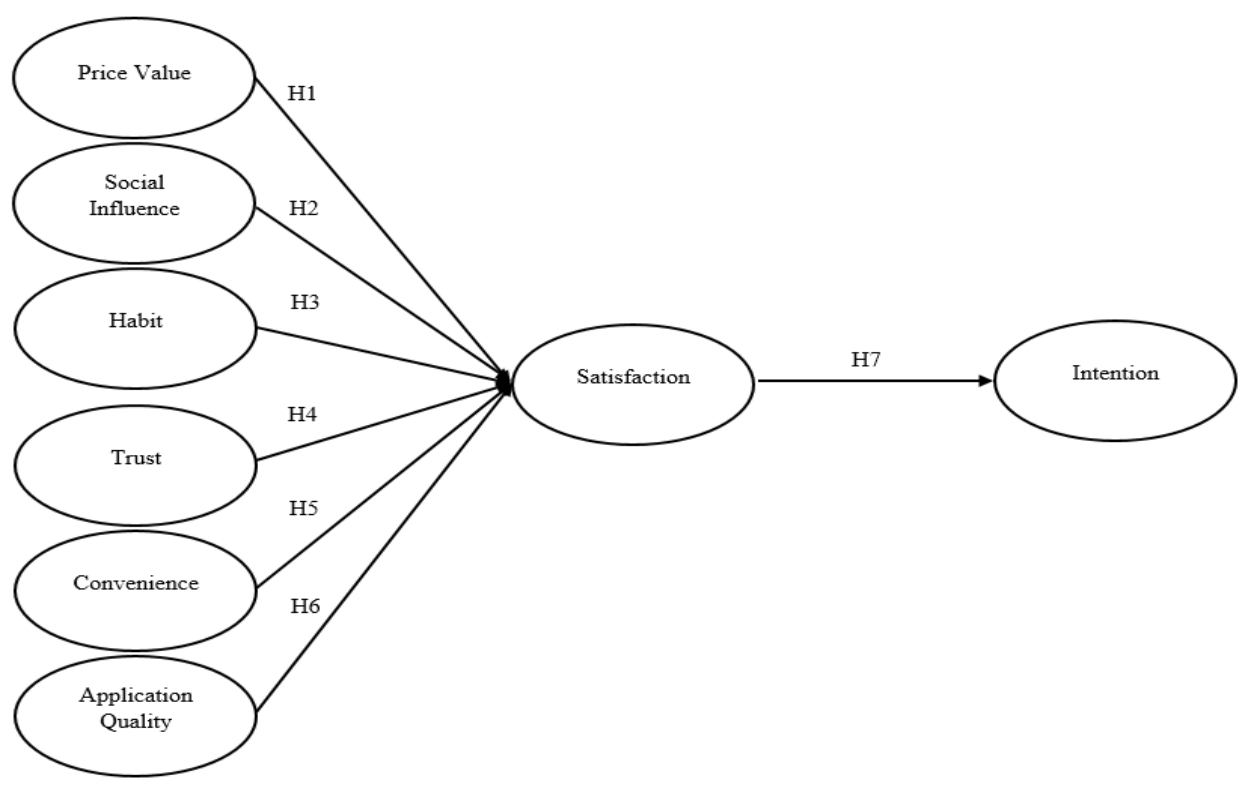

Figure 4. Research model.

Second, the empirical studies conducted by Wang et al. [30], Chi [21], and Jenny and Bahtiar [34] revealed that perceived quality is one of the dominant factors that positively influence customers' attitudes and intentions. Customers will continue to use food delivery apps if the providers continue to provide quality and meet their expectations. The results of the study conducted by Kapoor and Vij [11] support the importance of mobile app 
attributes like name, visuals, information, navigation, and collaboration design, finding that these factors influence customers' engagement when choosing a platform. Satisfaction is important for both customers and businesses. Keeping existing customers satisfied with one's goods or services matters even more than the price of the goods or services. Ample research has proven that most customers will choose to repurchase the product or service that made them most satisfied the first time they purchased it $[9,14,30]$.

Third, convenience means making the customer's experience easy and clear. There have been few studies where UTAUT2 is modified with the convenience concern. With the advent of food delivery apps, ordering and receiving a favorite food item, irrespective of time and location, have become more convenient than ever. Hence, apps should eliminate the roadblocks to maximizing convenience in order to facilitate serving customers better for longer. More importantly, there is a consensus in the literature that convenience is a key driver of customer engagement $[9,12]$.

One more key factor that is common among purchasing decisions is trust. Most studies related to transaction and online services have revealed that it is necessary to examine consumer trust $[9,23,25,29,61]$. The conceptual model, including the proposed hypothesis paths, is shown in Figure 4.

\subsection{Measurement Model}

The present study employed a nonprobability, self-selection sampling method. The survey instrument that was used to test the hypotheses and to propose a research model was developed from prior studies. The relevant measures and scales were adapted and slightly modified to demonstrate the research questions' consistency and validity. Modifications were made to fit the specific context of food delivery apps. The surveys were conducted in Thailand. The survey questionnaire was initially formulated in Thai by the researcher and was piloted on 20 users of food delivery apps in order to minimize the risks associated with measurement errors in the study. The recommendations from the pilot survey led to the modification and alteration of a few items to ascertain clarity and legibility. SPSS software was then used to ensure a level of internal consistency and reliability among the variables through Cronbach's alpha tests. All the constructs showed Cronbach's alpha values of $>0.8$, higher than the cut-off value of 0.7 [63]. A professional translator translated the survey questionnaire into English, ensuring high quality and consistency. The final survey questionnaire is presented in Appendix A. The scale items that were used to measure the construct were selected after an intensive and careful review of the relevant existing literature. We chose the questionnaires that had been developed based on an energetic body, a well-documented scale, and a good match with the current research context.

\subsection{Sampling and Data Collection}

The study hypotheses were tested using a quantitative approach. Kline [64] recommends that the minimum sample size required to examine the factors based on SEM is 200 respondents. Therefore, this paper accounts for over 200 respondents in the sample to meet the minimum requirement of conducting SEM analysis properly. The required data were collected from smartphone users who had already been using food delivery apps; this representative sample means we should be able to confidently generalize the results to the whole population of food delivery users. This study uses an online survey due to its major advantages over other modes of survey. An online survey has very minimal administration cost and is very convenient to diffuse among participants, facilitating ease of data entry and analysis [65]. In current times, most participants are internet users, and an online survey enables the participants to fill out the questionnaire in the most convenient way. An online survey was conducted to collect data via Google Forms by disseminating the instrument on the social media platform from August to October 2019, before the COVID-19 pandemic, and from April to May 2020, during the COVID-19 pandemic. The online survey was divided into two parts. The first part consisted of seven close-ended questions, generating the demographic profile of the subjects (for example, gender, age, education, income). 
The second part included the items of price value (adopted from Venkatesh et al. [31]), convenience (adopted from Liu et al. [66]), and application quality (adopted from Mutaz and Enas [67] and Wang et al. [30]). Trust was adopted from Xiao et al. [68]; social influence, habit, and intention to use were derived from Alalwan [14]; satisfaction was based on the instrument proposed by Ashfaq et al. [69]. Each item was evaluated using a 5-point Likert scale, ranging from "strongly disagree $=1$ " to "strongly agree $=5$." This research model contained eight constructs, with each construct measured by multiple items.

In the before-the-COVID-19-pandemic sample, 285 respondents participated in the online survey, but only the responses of 220 respondents were valid for further analysis after screening for missing data. As shown in Tables 1 and 2, it was found that the sample had almost equal numbers of males $(50.9 \%)$ and females $(49.1 \%)$. Most of the participants were $31-35$ years old $(32.73 \%)$, had a bachelor's degree $(70.91 \%)$, had a personal monthly income of US\$500-1000 (50.0\%), and were office workers (55.45\%). In terms of user behavior, most of the respondents (59.09\%) used food delivery apps only once a week, $40.45 \%$ reported spending below US $\$ 3.05$ per use, and $47.73 \%$ had been using food delivery apps for $1-2$ years.

Table 1. Descriptive statistics for the before- and during-the-COVID-19-pandemic samples.

\begin{tabular}{|c|c|c|c|c|c|}
\hline \multicolumn{2}{|c|}{ Construct } & \multicolumn{2}{|c|}{$\begin{array}{l}\text { Before-the-COVID-19-Pandemic } \\
\text { Sample }(\mathrm{N}=220)\end{array}$} & \multicolumn{2}{|c|}{$\begin{array}{l}\text { During-the-COVID-19-Pandemic } \\
\text { Sample (N = 250) }\end{array}$} \\
\hline $\begin{array}{l}\text { Demographic } \\
\text { Variable }\end{array}$ & Item & Frequency & Percentage (\%) & Frequency & Percentage $(\%)$ \\
\hline \multirow[t]{2}{*}{ Gender } & Male & 112 & 50.9 & 127 & 50.8 \\
\hline & Female & 108 & 49.1 & 123 & 49.2 \\
\hline \multirow[t]{5}{*}{ Age } & $<25$ & 28 & 12.7 & 33 & 13.2 \\
\hline & $25-30$ & 61 & 27.7 & 56 & 22.4 \\
\hline & $31-35$ & 75 & 32.7 & 80 & 32.0 \\
\hline & $36-40$ & 36 & 16.4 & 58 & 23.2 \\
\hline & $>40$ & 20 & 10.5 & 23 & 09.2 \\
\hline \multirow[t]{4}{*}{ Education } & High school & 12 & 05.5 & 23 & 09.2 \\
\hline & Vocational & 23 & 10.5 & 35 & 14.0 \\
\hline & Bachelor's degree & 156 & 70.9 & 150 & 60.0 \\
\hline & Master's degree & 29 & 13.2 & 42 & 16.8 \\
\hline \multirow[t]{5}{*}{ Income } & $<$ USD500 & 20 & 10.5 & 50 & 20.0 \\
\hline & USD500-1000 & 110 & 50.0 & 122 & 48.8 \\
\hline & USD1001-1460 & 74 & 33.6 & 68 & 27.2 \\
\hline & USD1461-2435 & 14 & 06.4 & 9 & 03.6 \\
\hline & >USD2435 & 2 & 00.5 & 1 & 00.4 \\
\hline \multirow[t]{6}{*}{ Occupation } & Unemployed & 12 & 05.5 & 7 & 02.8 \\
\hline & Self-employed & 35 & 15.9 & 55 & 22.0 \\
\hline & Office worker & 122 & 55.5 & 108 & 43.2 \\
\hline & $\begin{array}{l}\text { Government } \\
\text { officer }\end{array}$ & 10 & 04.6 & 45 & 18.0 \\
\hline & Student & 38 & 17.3 & 31 & 12.4 \\
\hline & Retired & 3 & 01.4 & 4 & 01.6 \\
\hline
\end{tabular}


Table 2. Characteristic statistics for the before- and during-the-COVID-19-pandemic samples.

\begin{tabular}{|c|c|c|c|c|c|}
\hline \multicolumn{2}{|c|}{ Construct } & \multicolumn{2}{|c|}{$\begin{array}{l}\text { Before-the-COVID-19-Pandemic } \\
\text { Sample }(\mathrm{N}=220)\end{array}$} & \multicolumn{2}{|c|}{$\begin{array}{l}\text { During-the-COVID-19-Pandemic } \\
\text { Sample (N = 250) }\end{array}$} \\
\hline $\begin{array}{c}\text { Characteristic } \\
\text { Variable }\end{array}$ & Item & Frequency & Percentage (\%) & Frequency & Percentage (\%) \\
\hline \multirow{5}{*}{$\begin{array}{l}\text { App use frequency } \\
\text { for } 1 \text { week }\end{array}$} & 1 time & 130 & 59.1 & 10 & 04.0 \\
\hline & $2-3$ times & 58 & 26.4 & 71 & 28.4 \\
\hline & 4-6 times & 23 & 10.5 & 109 & 43.6 \\
\hline & 7 times & 7 & 03.2 & 57 & 22.8 \\
\hline & $>7$ times & 2 & 00.9 & 3 & 01.2 \\
\hline \multirow{4}{*}{$\begin{array}{c}\text { Average } \\
\text { spending/use time }\end{array}$} & $<$ USD3.5 & 89 & 40.5 & 39 & 15.6 \\
\hline & USD3.5-10 & 62 & 28.2 & 99 & 39.6 \\
\hline & USD10.1-16 & 40 & 18.2 & 77 & 30.8 \\
\hline & Above USD16 & 29 & 13.2 & 35 & 14.0 \\
\hline \multirow[t]{3}{*}{ Use experience } & Up to 1 year & 85 & 38.6 & 165 & 66.0 \\
\hline & 1-2 years & 105 & 47.7 & 70 & 28.0 \\
\hline & $>2$ years & 30 & 13.6 & 15 & 06.0 \\
\hline
\end{tabular}

In the during-the-COVID-19-pandemic sample, 304 respondents participated in the online survey, but only 250 eligible responses were collected after screening for missing data. As shown in Tables 1 and 2, it was found that the sample had almost equal numbers of males $(50.8 \%)$ and females $(49.2 \%)$. Most of the participants were 31-35 years old $(32.0 \%)$, had a bachelor's degree $(60.0 \%)$, had a personal monthly income of US\$500-1000 $(48.8 \%)$, and were office workers $(43.2 \%)$. In terms of their app user behavior, most of the respondents (43.6\%) used food delivery apps $2-3$ times per week, $39.6 \%$ reported an average spend of US\$3.5-10 per use, and $66 \%$ had been using food delivery apps for up to 1 year. The empirical findings during the COVID-19 pandemic originated from the study conducted by Chotigo and Kadono [9].

As shown in Table 3, the mean values of the constructs ranged from 4.511 to 4.653 for the before-the-COVID-19-pandemic sample and from 4.388 to 4.568 for the during-theCOVID-19-pandemic sample. This reveals that both cases show a positive response to the factors being measured in this research. The skewness and kurtosis indices ranged from -2.295 to -0.825 and from -0.183 to 5.908 , respectively, for the before-the-COVID19-pandemic sample and from -1.792 to -1.115 and from 0.891 to 2.945 , respectively, for the during-the-COVID-19-pandemic sample. Data are considered normally distributed and acceptable if their skewness indices are within the range of -2 to 2 and if their kurtosis indices are within the range of -7 to 7 [70].

Table 3. Descriptive statistics of the constructs for the before- and during-the-COVID-19-pandemic samples.

\begin{tabular}{|c|c|c|c|c|c|c|c|c|}
\hline \multirow[t]{2}{*}{ Construct } & \multicolumn{4}{|c|}{ Before-the-COVID-19-Pandemic Sample } & \multicolumn{4}{|c|}{ During-the-COVID-19-Pandemic Sample } \\
\hline & Mean & Std. Deviation & Skewness & Kurtosis & Mean & Std. Deviation & Skewness & Kurtosis \\
\hline Price value & 4.645 & 0.440 & -1.159 & 0.953 & 4.503 & 0.692 & -1.415 & 0.891 \\
\hline Social influence & 4.596 & 0.495 & -1.274 & 1.134 & 4.388 & 0.743 & -1.115 & 0.165 \\
\hline Habit & 4.588 & 0.579 & -1.725 & 2.602 & 4.568 & 0.570 & -1.630 & 2.517 \\
\hline Trust & 4.583 & 0.566 & -1.880 & 3.727 & 4.531 & 0.573 & -1.576 & 2.302 \\
\hline Convenience & 4.562 & 0.494 & -1.085 & 0.932 & 4.452 & 0.691 & -1.338 & 0.953 \\
\hline Application quality & 4.635 & 0.412 & -0.825 & -0.183 & 4.535 & 0.651 & -1.744 & 2.945 \\
\hline Satisfaction & 4.511 & 0.683 & -1.407 & 1.134 & 4.505 & 0.725 & -1.544 & 1.422 \\
\hline Intention & 4.653 & 0.585 & -1.995 & 5.908 & 4.568 & 0.694 & -1.792 & 2.525 \\
\hline
\end{tabular}




\section{Data Analysis and Results}

This study used confirmatory factor analysis (CFA) based on AMOS 23.0 software to access factor structure and validate the model's scale. The congeneric model was examined for model fit, reliability, convergent validity, and discriminant validity. Following the recommendation of Hair et al. [70], the following indices were considered: the goodnessof-fit index (GFI), the normed-fit index (NFI), root mean square error of approximation (RMSEA), root mean square residuals (RMSRs), standardized root mean residual (SRMR), the comparative-fit index (CFI), and the Tucker-Lewis index (TLI). The primary model consisted of eight constructs with 27 indicators: price value $(\mathrm{PV})=3$ indicators; social influence $(\mathrm{S})=3$ indicators; habit $(\mathrm{H})=3$ indicators; trust $(\mathrm{T})=3$ indicators; convenience $(\mathrm{C})=3$ indicators; application quality $(\mathrm{AQ})=6$ indicators; satisfaction $(\mathrm{SAT})=3$ indicators; intention (I) $=3$ indicators. Table 4 shows the model's summary fit with the initial and final measurement models of the before- and during-the-COVID-19-pandemic samples. It shows that both samples had GFI values that were lower than the recommended level. Hence, to improve the model fit, some items must be removed based on modification indices, factor loading $(<0.5)$, and standardized residuals [70].

Table 4. Results of the measurement model.

\begin{tabular}{cccccc}
\hline & & \multicolumn{2}{c}{$\begin{array}{c}\text { Before-the-COVID-19- } \\
\text { Pandemic } \\
\text { Sample }\end{array}$} & \multicolumn{2}{c}{$\begin{array}{c}\text { During-the-COVID-19- } \\
\text { Pandemic } \\
\text { Sample }\end{array}$} \\
\hline Fit Indices & $\begin{array}{c}\text { Cut-Off } \\
\text { Point }\end{array}$ & Initial & Modified & Initial & Modified \\
\hline$x^{2} / \mathrm{df}$ & $<3$ & 1.456 & 1.233 & 1.797 & 1.377 \\
GFI & $>0.90$ & 0.877 & 0.910 & 0.854 & 0.908 \\
RMSEA & $<0.08$ & 0.046 & 0.033 & 0.057 & 0.039 \\
RMSR & $<0.05$ & 0.015 & 0.013 & 0.019 & 0.015 \\
SRMR & $<0.08$ & 0.049 & 0.0385 & 0.033 & 0.027 \\
NFI & $>0.80$ & 0.888 & 0.924 & 0.917 & 0.943 \\
CFI & $>0.90$ & 0.961 & 0.985 & 0.961 & 0.984 \\
TLI & $>0.90$ & 0.954 & 0.981 & 0.954 & 0.980 \\
\hline
\end{tabular}

4.1. Measurement Model Results: Model Fitness Tested Initially via Confirmatory Factor Analysis, Followed by Evaluation of the Reliability and Validity Construct

To achieve an acceptable model fit and to confirm that the research model is appropriate for predicting food delivery app adoption intention, it was necessary to eliminate 3 of the original 27 indicators of each sample. Scale items AQ4, AQ5, and AQ6 were deleted from the initial measurement model for the before-the-COVID-19-pandemic sample, and scale items AQ2, AQ3, and AQ4 were deleted from the initial measurement model for the during-the-COVID-19-pandemic sample. However, the final scale items were appropriately balanced to retain a minimum of three items per scale, which can prevent criticism for the circumvention of possible identification and convergence problems [71]. The indices' results, along with their recommended level of indices fit, are shown in Table 4; we conclude that in the modified measurement model, the GFI values met the recommended level, suggesting that the research model provides a good fit for the data [70].

To validate the construct of the proposed model, we examined convergent validity and discriminant validity. Convergent validity is evaluated by measuring standardized path loadings, composite reliability (CR), and average variance extracted (AVE) to prove reliability and validity. As shown in Tables 5 and 6 , in all the reflective construct items, the item loadings ranged from 0.712 to 0.951 before the COVID-19 pandemic and from 0.760 to 0.912 during the COVID-19 pandemic, indicating that both samples had conformity to the factor loading estimates of Hair et al. (2010), who reported that they should be higher than 0.5 and, ideally, 0.7 or higher. The index values of CR and AVE ranged from 0.772 to 0.946 and from 0.597 to 0.854 , respectively, before the COVID-19 pandemic and from 
0.835 to 0.928 and from 0.684 to 0.812 , respectively, during the COVID-19 pandemic. CR is usually satisfied by the recommended value of 0.7 (for an exploratory study, 0.6 could be accepted; Hair et al., 2010), and the recommended index value of AVE should exceed 0.5 [72]. This finding for both samples indicated that the scale items met the convergent validity requirement, and all the indicators were closely related to the given construct. Additionally, there is discriminant validity when the square root of AVE in each construct is greater than the interconstruct correlation value [73]. Tables 7 and 8 show that both samples' discriminant validity is sufficient and satisfactory for all the constructs. This suggests that the research model meets the criteria for supporting discriminant validity.

Table 5. Construct reliability and validity for the before-the-COVID-19-pandemic sample.

\begin{tabular}{|c|c|c|c|c|c|}
\hline Construct & Items & $\begin{array}{l}\text { Standardized } \\
\text { Loading }\end{array}$ & $\begin{array}{l}\text { Composite } \\
\text { Reliability }\end{array}$ & $\begin{array}{l}\text { Average Variance } \\
\text { Extracted }\end{array}$ & $\mathbf{R}^{2}$ \\
\hline \multirow{3}{*}{ Price value (PV) } & PV1 & 0.810 & 0.836 & 0.630 & \\
\hline & PV2 & 0.824 & & & \\
\hline & PV3 & 0.745 & & & \\
\hline \multirow{3}{*}{$\begin{array}{l}\text { Social influence } \\
\text { (SI) }\end{array}$} & SI1 & 0.836 & 0.816 & 0.597 & \\
\hline & SI2 & 0.756 & & & \\
\hline & SI3 & 0.721 & & & \\
\hline \multirow{3}{*}{ Habit (HT) } & HT1 & 0.806 & 0.876 & 0.703 & \\
\hline & HT2 & 0.878 & & & \\
\hline & HT3 & 0.829 & & & \\
\hline \multirow{3}{*}{ Trust (T) } & $\mathrm{T} 1$ & 0.819 & 0.846 & 0.647 & \\
\hline & $\mathrm{T} 2$ & 0.834 & & & \\
\hline & T3 & 0.758 & & & \\
\hline \multirow{3}{*}{ Convenience (C) } & $\mathrm{C} 1$ & 0.816 & 0.863 & 0.678 & \\
\hline & $\mathrm{C} 2$ & 0.830 & & & \\
\hline & $\mathrm{C} 3$ & 0.824 & & & \\
\hline \multirow{3}{*}{$\begin{array}{l}\text { Application } \\
\text { quality (AQ) }\end{array}$} & AQ1 & 0.712 & 0.772 & 0.530 & \\
\hline & AQ22 & 0.722 & & & \\
\hline & AQ3 & 0.750 & & & \\
\hline \multirow{3}{*}{ Satisfaction (SAT) } & Sa1 & 0.929 & 0.946 & 0.854 & 0.630 \\
\hline & $\mathrm{Sa} 2$ & 0.951 & & & \\
\hline & $\mathrm{Sa} 3$ & 0.892 & & & \\
\hline \multirow{3}{*}{ Intention (I) } & I1 & 0.890 & 0.923 & 0.801 & 0.410 \\
\hline & $\mathrm{I} 2$ & 0.882 & & & \\
\hline & I3 & 0.912 & & & \\
\hline
\end{tabular}


Table 6. Construct reliability and validity for the during-the-COVID-19-pandemic sample.

\begin{tabular}{|c|c|c|c|c|c|}
\hline Construct & Items & $\begin{array}{l}\text { Standardized } \\
\text { Loading }\end{array}$ & $\begin{array}{l}\text { Composite } \\
\text { Reliability }\end{array}$ & $\begin{array}{l}\text { Average Variance } \\
\text { Extracted }\end{array}$ & $\mathbf{R}^{2}$ \\
\hline \multirow{3}{*}{ Price value (PV) } & PV1 & 0.839 & 0.890 & 0.730 & \\
\hline & PV2 & 0.852 & & & \\
\hline & PV3 & 0.872 & & & \\
\hline \multirow{3}{*}{$\begin{array}{l}\text { Social influence } \\
\text { (SI) }\end{array}$} & SI1 & 0.891 & 0.890 & 0.730 & \\
\hline & SI2 & 0.905 & & & \\
\hline & SI3 & 0.760 & & & \\
\hline \multirow{3}{*}{ Habit (HT) } & HT1 & 0.828 & 0.867 & 0.684 & \\
\hline & HT2 & 0.823 & & & \\
\hline & HT3 & 0.831 & & & \\
\hline \multirow{3}{*}{ Trust (T) } & $\mathrm{T} 1$ & 0.818 & 0.835 & 0.629 & \\
\hline & $\mathrm{T} 2$ & 0.763 & & & \\
\hline & T3 & 0.797 & & & \\
\hline \multirow{3}{*}{ Convenience (C) } & $\mathrm{C} 1$ & 0.831 & 0.885 & 0.720 & \\
\hline & $\mathrm{C} 2$ & 0.871 & & & \\
\hline & $\mathrm{C} 3$ & 0.843 & & & \\
\hline \multirow{3}{*}{$\begin{array}{l}\text { Application } \\
\text { quality (AQ) }\end{array}$} & AQ1 & 0.844 & 0.910 & 0.772 & \\
\hline & AQ5 & 0.906 & & & \\
\hline & AQ6 & 0.885 & & & \\
\hline \multirow{3}{*}{ Satisfaction (SAT) } & Sa1 & 0.912 & 0.928 & 0.812 & 0.770 \\
\hline & Sa2 & 0.902 & & & \\
\hline & $\mathrm{Sa} 3$ & 0.889 & & & \\
\hline \multirow{3}{*}{ Intention (I) } & I1 & 0.846 & 0.916 & 0.785 & 0.710 \\
\hline & $\mathrm{I} 2$ & 0.902 & & & \\
\hline & I3 & 0.908 & & & \\
\hline
\end{tabular}

Table 7. Discriminant validity of the measurement model for the before-the-COVID-19-pandemic sample.

\begin{tabular}{ccccccccc}
\hline Variable & PV & SI & HT & T & C & AQ & SAT & I \\
\hline Price value (PV) & $\mathbf{0 . 7 9 4}$ & & & & & & & \\
Social influence (SI) & 0.431 & $\mathbf{0 . 7 7 3}$ & & & & & & \\
Habit (HT) & 0.429 & 0.733 & $\mathbf{0 . 8 3 8}$ & & & & & \\
Trust (T) & 0.425 & 0.598 & 0.742 & $\mathbf{0 . 8 0 4}$ & & & & \\
Convenience (C) & 0.260 & 0.151 & 0.262 & 0.171 & $\mathbf{0 . 8 2 3}$ & & & \\
Application quality (AQ) & 0.471 & 0.415 & 0.443 & 0.433 & 0.280 & $\mathbf{0 . 7 2 8}$ & & \\
Satisfaction (SAT) & 0.506 & 0.644 & 0.685 & 0.644 & 0.302 & 0.540 & $\mathbf{0 . 9 2 4}$ & \\
Intention (I) & 0.426 & 0.598 & 0.658 & 0.655 & 0.210 & 0.326 & 0.619 & $\mathbf{0 . 8 9 5}$
\end{tabular}

The boldface number in the diagonal row represents the value of the square root of the average variance extracted (AVE) value for each latent construct, while the value below represents the squared interconstruct correlations.

Table 8. Discriminant validity of the measurement model for the during-the-COVID-19-pandemic sample.

\begin{tabular}{ccccccccc}
\hline Variable & PV & SI & HT & T & C & AQ & SAT & I \\
\hline Price value (PV) & $\mathbf{0 . 8 5 4}$ & & & & & & & \\
Social influence (SI) & 0.836 & $\mathbf{0 . 8 5 4}$ & & & & & & \\
Habit (HT) & 0.754 & 0.764 & $\mathbf{0 . 8 2 7}$ & & & & & \\
Trust (T) & 0.643 & 0.707 & 0.771 & $\mathbf{0 . 7 9 3}$ & & & & \\
Convenience (C) & 0.639 & 0.675 & 0.756 & 0.728 & $\mathbf{0 . 8 4 8}$ & & & \\
Application quality (AQ) & 0.719 & 0.765 & 0.779 & 0.750 & 0.707 & $\mathbf{0 . 8 7 9}$ & & \\
Satisfaction (SAT) & 0.653 & 0.714 & 0.670 & 0.715 & 0.677 & 0.823 & $\mathbf{0 . 9 0 1}$ & \\
Intention (I) & 0.718 & 0.769 & 0.692 & 0.767 & 0.728 & 0.791 & 0.798 & $\mathbf{0 . 8 8 6}$ \\
\hline
\end{tabular}

The boldface number in the diagonal row represents the value of the square root of the average variance extracted (AVE) value for each latent construct, while the value below represents the squared interconstruct correlations. 


\subsection{Structural Model Results: Path Coefficient Analysis}

To analyze the structural model, as shown in Figures 5 and 6, the model, path coefficients, and $\mathrm{R}^{2}$ for the endogenous construct were tested. The fit indices of the structural model of the before-the-COVID-19-pandemic sample were $x^{2} / \mathrm{df}=1.395$, GFI $=0.897$, $\mathrm{AGFI}=0.866, \mathrm{NFI}=0.912, \mathrm{CFI}=0.973$, and RMSEA $=0.042$, whereas those of the structural model of the during-the-COVID-19-pandemic sample were $x^{2} / \mathrm{df}=1.613(371.20 / 230$; $p=0.000)$, GFI $=0.892$, AGFI $=0.859, \mathrm{NFI}=0.931, \mathrm{CFI}=0.972$, and RMSEA $=0.050$. These fit measures are comparable to those obtained with the CFA and showed a good fit measure [70].

Figure 5 shows that the path coefficients of the before-the-COVID-19-pandemic sample are all significant. Significant paths were found at the $p=0.001,0.05$, and 0.1 levels, with the price value-to-satisfaction path at $p=0.060$; the social influence-to-satisfaction path at $p=0.012$; the habit-to-satisfaction path at $p=0.047$; the trust-to-satisfaction path at $p=0.013$; the convenience-to-satisfaction path at $p=0.080$; the application quality-to-satisfaction path at $p=0.014$; the satisfaction-to-intention path at $p=0.000$. The results also revealed that the price value-to-satisfaction path coefficient was $\beta=0.12$; the social influence-to-satisfaction path $\beta=0.23$ was the strongest path to satisfaction; the habit-to-satisfaction path $\beta=0.22$, the trust-to-satisfaction path $\beta=0.22$, and the convenience-to-satisfaction path $\beta=0.10$ were relatively lower than the other paths to satisfaction; the application quality-to-satisfaction path was $\beta=0.17$, while the satisfaction-to-intention path was $\beta=0.64$.

The $R^{2}$ measure is used to explain the proportion of the dependent variable influenced by the independent variables. The overall $R^{2}$ values for satisfaction and adoption intention for the before-the-COVID-19-pandemic sample show that the proportions of the dependent variables that were influenced by the independent variables were 0.63 and 0.41 , respectively, which are considered moderate and low, respectively (see Table 6 or Figure 5). The model testing in Figure 5 shows that all the seven items in the hypotheses are significant factors, but price value (H1) and convenience (H5) are supported at a significance level of $p<0.10$; social influence (H2), habit (H3), trust (H4), and application quality (H6) are supported at a significance level of $p<0.50$; satisfaction (H7) is supported at a significance level of $p<0.001$. To summarize, the model provides support for the hypothesis that satisfaction has been influenced by price value, social influence, habit, trust, convenience, and application quality before the COVID-19 pandemic and can explain 63\% of all the variances. Additionally, customer intention toward food delivery app adoption is influenced by satisfaction and can explain $41 \%$ of all the variances.

Figure 6 shows the path coefficients of the during-the-COVID-19-pandemic sample. The sample revealed both significant and nonsignificant paths. Significant paths were found at the $p=0.001,0.05$, and 0.1 levels, with the price value-to-satisfaction path at $p=0.638$; the social influence-to-satisfaction path at $p=0.096$; the habit-to-satisfaction path at $p=0.092$; the trust-to-satisfaction path at $p=0.024$; the convenience-to-satisfaction path at $p=0.036$; the application quality-to-satisfaction path at $p=0.000$; the satisfactionto-intention path at $p=0.000$. The results also revealed that the price value-to-satisfaction path coefficient $(\beta=0.04)$, the social influence-to-satisfaction path coefficient $(\beta=0.17)$, the habit-to-satisfaction path coefficient $(\beta=-0.17)$, the trust-to-satisfaction path coefficient ( $\beta=0.20)$, the convenience-to-satisfaction path coefficient $(\beta=0.16)$, and the application quality-to-satisfaction path coefficient $(\beta=0.56)$ were relatively stronger than the other paths to satisfaction and that the satisfaction-to-intention path coefficient was $\beta=0.84$.

The overall $R^{2}$ for satisfaction and adoption intention for the during-the-COVID-19pandemic sample show that the proportions of the dependent variable influenced by the independent variables were 0.77 and 0.71 , respectively, which are considered strong (see Table 7 or Figure 6). The model testing in Figure 6 shows that one of the seven items in the hypotheses, price value (H1), is nonsignificant; social influence $(\mathrm{H} 2)$ and habit (H3) are supported at a significance level of $p<0.10$; trust (H4) and convenience (H5) are supported at a significance level of $p<0.05$; application quality (H6) and satisfaction (H7) are supported at a significance level of $p<0.001$. To summarize, the model provides 
support for six hypotheses $(\mathrm{H} 2-\mathrm{H} 7)$ in their predicted directions, whereas the influence of price value on satisfaction toward adoption intention is not supported. To summarize, the model provides support for the hypothesis that satisfaction is influenced by social influence, habit, trust, convenience, and application quality and can explain $77 \%$ of all the variances. Additionally, customer intention toward food delivery app adoption is influenced by satisfaction and can explain $71 \%$ of all the variances.

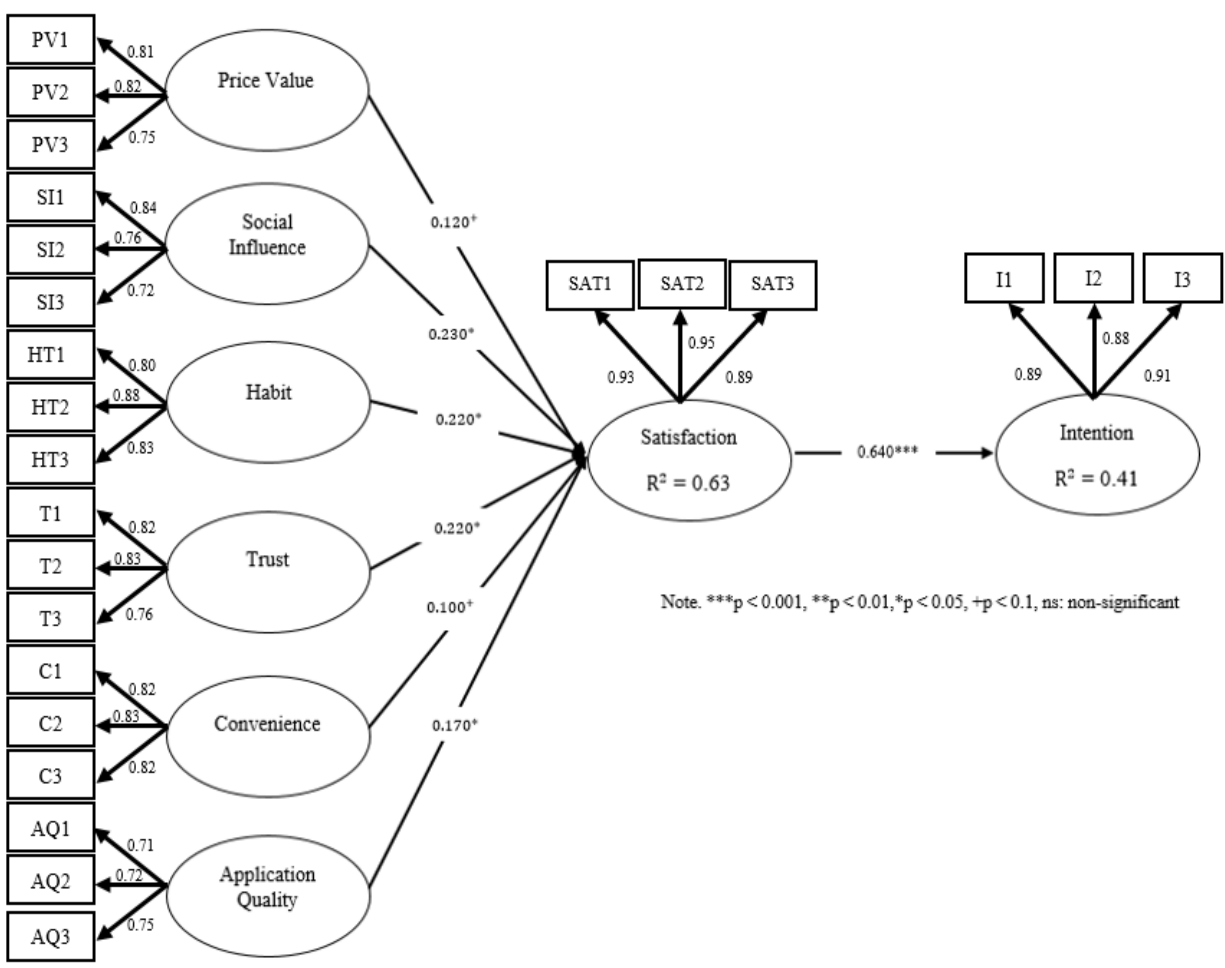

Figure 5. Results of structural modeling analysis for the before-the-COVID-19-pandemic sample.

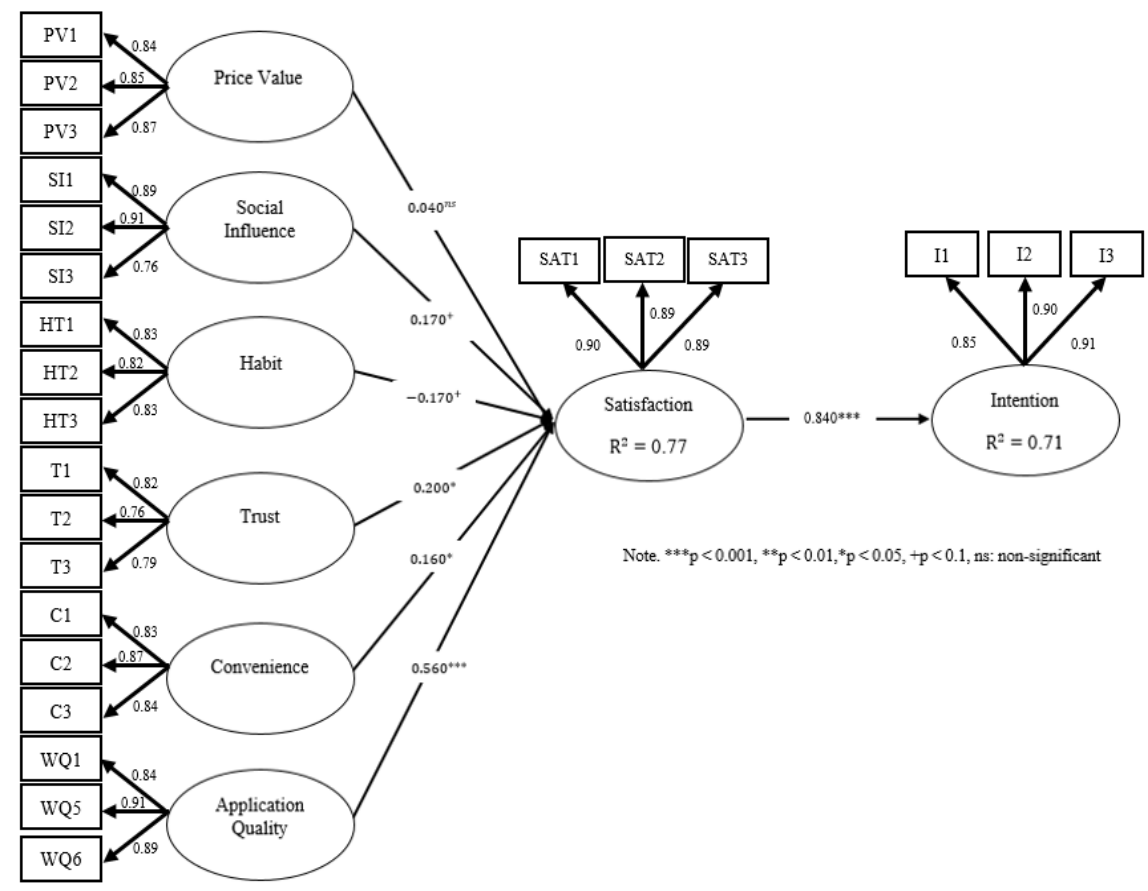

Figure 6. Results of structural modeling analysis for the during-the-COVID-19-pandemic sample. 


\section{Discussion}

As shown in Table 1, approximately equal gender distributions were observed in both samples. Moreover, in both the before- and during-the-COVID-19-pandemic samples, the study participants were predominantly young. Table 2 shows that before the COVID-19 outbreak, most food delivery app users used the app, on average, once a week. However, during the COVID-19 pandemic, most of the food delivery app users used the app 4-6 times a week, representing a significant increase. Additionally, the average cost incurred using food delivery apps during the COVID-19 pandemic was also higher, averaging 2-3 times higher than before. In addition, it was found that during the COVID-19 pandemic, the number of new food delivery app customers increased dramatically. Moreover, approximately $80 \%$ more people had been using food delivery apps for up to 2 years. Table 3 shows that the study participants in both samples responded positively ("strongly agree") to the factors that were measured in the study. Figures 5 and 6 show that customer intention to use a food delivery app, both before and during the COVID-19 pandemic, was influenced by satisfaction. In addition, the results supported the hypotheses that price value, social influence, habit, convenience, trust, and application quality had a significantly positive effect on satisfaction before the COVID-19 pandemic, while the influence of price value on satisfaction found no support; habit was found to have an inverse impact on satisfaction during the COVID-19 pandemic.

The study results showed that price value was a significant predictor of satisfaction before the COVID-19 pandemic. This demonstrates that before the COVID-19 pandemic, Thai customers seemed to obtain satisfaction from the use of a food delivery app on the basis of price value. Therefore, increasing the level of perceived monetary benefits and the utility of food delivery apps made customers more likely to be satisfied and to adopt food delivery apps before the pandemic. A similar result was found in the mobile food-ordering app context in Jordan [14], where the fact that price value plays a critical role in predicting satisfaction is empirically accepted. Conversely, the finding from the during-the-COVID19-pandemic sample failed to confirm the role of price value in forming satisfaction. This indicates that Thai customers' satisfaction with the use of a food delivery app toward such app's adoption during the pandemic is less affected by price value. This may be explained by the fact that the number of COVID-19 cases is increasing every day and that the Thai customers' fear of contracting COVID-19 drives them to try to protect themselves by practicing social distancing. Using food delivery apps to purchase food items is the best way to protect oneself from contracting COVID-19 due to its user convenience and availability. Moreover, restaurants have reduced food prices during the pandemic, which creates higher levels of perceived and actual values for the user. These factors help reduce the customers' perceived cost of using food delivery apps. Therefore, customers are more likely to order their desired food items through food delivery apps regardless of the price value; their satisfaction is likely to be less affected by price value. Chotigo and Kadono [9] also explained that Thai customers' free-of-charge access to food delivery apps, the more accessible delivery fees, and the necessity of avoiding crowds and exposure risk during the COVID-19 pandemic reduce the importance of price value when using food delivery apps. Hence, it seems that price value has played a trivial role so far in food delivery app adoption during the current COVID-19 pandemic.

Social influence was confirmed to be a significant factor determining satisfaction both before and during the COVID-19 pandemic, securing the highest significance before the COVID-19 pandemic $(\beta=0.23 ; p<0.10)$ compared to other factors. This finding is contrary to that of Alalwan [14], who showed that social influence is not significant in predicting satisfaction in Jordan. Nonetheless, Chotigo and Kadono [9] indicated that Thai customers' perspectives regarding the use of food delivery apps during the COVID-19 pandemic seem to conform to the views with social support or the views of influencers, such as comments or reviews from social networks, advertising, and valuable references (family, friends, or colleagues). This feedback can spark specific emotional triggers that influence customers' feelings and interest in the use of food delivery apps. 
Habit proved to be a significant factor determining satisfaction before the COVID-19 pandemic. In other words, Thai customers who were in the habit of using food delivery apps were more likely to obtain more satisfaction or enjoyment from using these. However, habit was found to be negatively correlated with satisfaction during the COVID-19 pandemic $(\beta=-0.17 ; p<0.10)$. The study conducted by Chotigo and Kadono [9] during the COVID-19 pandemic revealed that the negative relationship between habit and satisfaction could be explained by the fact that Thai customers attempted to resume the old normal, such as dining out at restaurants, veering away from home activities, and socializing, after being stuck at home for a long time and relying on the use of food delivery apps. Moreover, less reinforcement of the new habit or perceiving prepandemic behavior as posing a low risk would mean that the old habit is more likely to return quickly. These circumstances may be the cause of the negative relationship between habit and satisfaction over time.

Trust is a factor that was shown to play an important role as a predictor of satisfaction in both study samples, a finding that coincides with the results of several studies, such as $[9,45-47]$. This means that Thai customers seem to obtain more satisfaction if food delivery apps fulfill their promises, encourage customer trust, and ensure that their security practices are foolproof, making customer data safe and not vulnerable to being compromised by malicious actors. Furthermore, Chotigo and Kadono's [9] study finding during the current COVID-19 pandemic supported the view that food delivery apps are still new to Thai customers, and, as such, promoting trust can raise customer awareness and increase the adoption of food delivery apps. However, Thai customers have questions about food and food delivery safety, as safe and contactless operations have become a top priority for consumers due to the pandemic. It is thus suggested that to establish customer trust, particularly during the current COVID-19 pandemic, food delivery service operators should set and observe safety guidelines and should advertise these to make the customers fully aware of how they safely handle and transport food and ensure that customer contact is kept to a minimum.

Convenience was confirmed to have a crucial impact on satisfaction in both study samples. This shows the crucial role of convenience in shaping customer experience and satisfaction. This result has been supported by previous studies in various fields, such as $[9,12,32]$. Thai customers are more likely to be satisfied with using food delivery apps if they are ensured an experience that is easier, more convenient, saves energy, and is more time-efficient, as shown by Chotigo and Kadono [9]. Such relationships can be explained by the fact that the particular nature of the customers using food delivery apps requires the convenience of use of such apps.

Application quality was found to be significant in both samples and was found to be the most significant factor affecting food delivery app customer satisfaction during the COVID-19 pandemic $(\beta=0.56 ; p<0.001)$. The positive role of perceived quality has been supported by prior studies in the mobile commerce context $[9,21,30,56]$ and in the context of learning management systems [34]. As discussed by Chotigo and Kadono [9], Thai customers' satisfaction with the use of food delivery apps, toward the adoption of such apps during the pandemic, seems to be most affected by their attention to the quality of such apps. There are many approaches that food delivery operators can use to boost their customers' sense of pleasure, including ensuring app system quality, information quality, and service quality $[9,30,56]$. This finding also shows that customers require food delivery apps to be effective and accessible and to provide a seamless experience. The huge difference between the path coefficients of the before- and during-the-COVID-19pandemic samples can be explained by the fact that application quality remains a big concern and a major barrier to forming customer satisfaction toward food delivery app adoption, especially during the current COVID-19 pandemic, when food delivery apps have come to face rapidly increasing numbers of users and usage. Therefore, food delivery apps can offer a great user experience, improve system stability, and eliminate bugs by paying proper attention to quality assurance testing, which is likely to help make the customers satisfied with the use of the app and, thus, more likely to use it again. 
The statistical findings of this study strongly supported the hypothesis that satisfaction is the most critical factor predicting intention to use a food delivery app in both samples. Several prior studies on mobile food-ordering apps also showed a significant effect of satisfaction on intention to use $[9,14,28,30]$. The study conducted by Chotigo and Kadono [9] on food delivery apps during the pandemic concluded that increasing the level of customer satisfaction and providing a great app user experience to customers can make it more likely for the customers to continue using a food delivery app. Furthermore, customers seem to have the intention of continuing the use of a food delivery app if they are satisfied with their experience with it [14].

\subsection{Theoretical Implication}

To define our model, we modified the UTAUT2 model, eliminating the nonsignificant factors and adding a set of values related to food delivery apps by including the quality part of the ISs success model, convenience, trust, and satisfaction to explore and clarify customer intention of adopting food delivery apps [9]. The present study exhibited the differential responses to food delivery apps before and during the COVID-19 pandemic. Moreover, the study shed light on the mechanisms of trust, convenience, and application quality and showed these factors to be worth examining when studying food delivery apps. The study also validated the critical role of satisfaction in forming customer intention to use a food delivery app, as well as the roles of convenience, trust, and application quality in forming customer satisfaction that leads to the adoption of a food delivery app. Furthermore, the study investigated the distinct role of proposed factors in the dynamics of satisfaction and food delivery app adoption intention and strengthened the extant literature $[14,30]$ by examining each component's different impact on the model.

\subsection{Practical Implication}

Food delivery apps are changing the food industry by offering people an alternative to how they used to order food and get food delivered to their door. Moreover, the COVID-19 pandemic has spurred an incredible increase in new food delivery app customers. This holds true in both developing or developed countries, thus requiring tailored approaches for optimal adoption with appropriate plans. The results of this study can help marketers formulate the proper strategies for the successful operation of food delivery apps. Marketers should focus particularly on social influence, trust, convenience, and application quality to drive customer satisfaction, which is of paramount importance to promoting technology use. On the other hand, it can be said that while the prepandemic marketer greatly benefited from promoting price value and improving habit and social influence, during the pandemic and postpandemic, the marketer must reconsider the roles of price value and habit [9].

Most pre-COVID-19 Thai customers were interested in the monetary benefits of using food delivery apps. Merhi et al. [23] found that to boost service price value, it is necessary to charge a fair price by controlling the cost-effectiveness of the service. Therefore, marketers should pay particular attention to increasing the perceived value of their product or service, which will help improve customer satisfaction. However, during the pandemic, the benefit of the convenience of using food delivery apps reduces the cost of using such apps, as perceived by customers [9].

Both before and during the pandemic, food delivery app users showed considerable interest in accessing such apps through social media platforms. As customers can easily access social media platforms wherever they may be, the use of apps can be effectively promoted through such platforms at a minimum cost $[25,26]$. In this regard, marketing plans should focus more on promotional campaigns or marketing advertising via social media. This can help convince people to use the app and can enhance people's awareness of the brand. Moreover, during the pandemic, promoting the safety of using food delivery apps is helpful, effective, and persuasive, making the old and new customers aware of the 
benefits of using such apps and, thus, increasing their trust in the app, which can trigger their intention to adopt the app or to intensify their use of it [9].

Habit was found to play a crucial role in enhancing customer satisfaction before the pandemic, providing potential customers some motivation and making it easy for them to obtain the rewards of using the food delivery app elicited a good response [29]. Rewarding customers for using the food delivery app means providing them with a feel-good stimulus and delivering on one's promises [37]. In addition, to develop habitual responses from customers, marketers should plan the formation of customer habits. Increasing the accessibility of the app, maintaining its performance consistency, and preserving its gain efficiency and effectiveness will stimulate and encourage desirable habitual behavior on the part of customers. Nevertheless, during the COVID-19 pandemic, customers have come to adapt to home confinement and technologies for a prolonged period of time, which can reduce their satisfaction with using such technologies, particularly those who love outdoor activities [9].

Building customer trust is one of the best ways to generate customer satisfaction with the use of a food delivery app. Hence, aspects related to developing customer trust must be focused on by app marketers. To demonstrate credibility, a food delivery app must offer food references and must act as a trusted food advisor [29,61]. The app must always be available for use, and brand visibility must be built in some way for the customer who needs to use a food delivery app. If customers experience a problem with the use of the app and receive prompt, helpful, and memorable customer service, they are likely to develop trust in the app and to increase their use of it [25]. Furthermore, marketers have to ensure the security and reliability of their food delivery app to prevent customer experience of any malicious activity (e.g., usage, transaction). Moreover, during the pandemic, guaranteeing food safety in the handling, preservation, packaging, and logistic methods used to minimize the risk of customer exposure to the dreaded virus will help enhance customers' trust in the app and build customer loyalty [9].

This study also proves that both before and during the COVID-19 pandemic, customer satisfaction has been derived from the convenience of using food delivery apps. Making the customer experience of using the app easy and clear and showing that the app values the customers' time will keep the customers happy and loyal. Allowing the customers to schedule delivery appointments online to fit their schedule will also boost the convenience of using the app [50-52]. To enhance customer satisfaction, food delivery service operators should target optimal delivery speed, time, and effort by allowing customers to place orders quickly and keep track of their food deliveries. These will add value to a food delivery app from the customers' perspective and will promote customer satisfaction. Chotigo and Kadono [9] found that during the pandemic, safe food delivery, provision of more food options and better offers, and faster delivery fitting the customer's lifestyle will also improve customer satisfaction.

Developing a high-quality app that can be simply and quickly accessed and is useful, easy to use, and responsive will promote a positive user experience [21,30]. Therefore, app marketers should improve the performance and effectiveness of their app. Providing high-quality food information and a high-quality food delivery service were also found to be effective ways of gaining customer loyalty both before and during the pandemic by providing a better user experience with the app. Furthermore, particularly during the pandemic, an add-in virus exposure notification function in a food delivery app to alert users when they are ordering food in or near a high-COVID-19-infection-risk area will help customers decide whether to order food from safer places and, thus, enhance the customer experience of using the app [9].

To draw customer intention to use a food delivery app, creating customer satisfaction has been highly important both before and during the pandemic. Thai customers in this study expressed their intention to use a food delivery app if they are satisfied with it. Customers want to be treated fairly; as such, if food delivery service app operators improve their services and meet their customers' expectations, customer satisfaction with 
their services will increase $[14,27,33,56]$. Food delivery service managers first need to understand their customers (to the extent that this is possible), persevere in meeting their customers' expectations, and reach out to their customers in positive ways while convincing them to keep using the food delivery app. This will help the customers perceive highly personalized treatment from the food delivery service provider, which will yield better business results by increasing customer satisfaction and leading the customers to keep using the food delivery app.

\section{Conclusions}

The drivers of digital commerce in Thailand are in line with broader social trends, particularly the rapid growth in the number of mobile phone users. The $72 \%$ penetration rate of the mobile phone user base in Thailand in 2019 is expected to grow to $87 \%$ by 2025 [74]. The convenience and accessibility (using smartphones) of ordering food, coupled with fast delivery and the availability of various payment options, are shifting consumer behavior from dining outside to ordering food through doorstep services. The growing number of mobile phone users and the COVID-19 pandemic have spurred and accelerated the adoption of food delivery apps. This study attempts to reveal and examine the main factors shaping Thai customer satisfaction with food delivery apps and their willingness to use them. In addition, understanding the main drivers of customers' adoption of food delivery apps in different settings will help marketers propose appropriate strategies, reach potential customers, reduce their operating costs, and realize a higher revenue.

This research provides a comprehensive view of Thai customers' use of food delivery apps in two cases: before and during the COVID-19 pandemic. The proposed model was obtained by revising the conceptual paradigms of the UTAUT2 model; the factors that did not fit the study context were eliminated, and four other constructs (convenience, trust, application quality, and satisfaction) were incorporated. The hypotheses considered in the study is supported by empirical analysis. Before the pandemic, it is evident that price value $(\mathrm{H} 1)$, social influence $(\mathrm{H} 2)$, habit $(\mathrm{H} 3)$, trust $(\mathrm{H} 4)$, convenience $(\mathrm{H} 5)$, and application quality (H6) significantly influenced satisfaction, and, in turn, satisfaction (H7) impacts intention to use. On the contrary, during COVID 19 pandemic, the analysis supported only $\mathrm{H} 2-\mathrm{H} 7$, while no evidence was realized on the influence of price $(\mathrm{H} 1)$ on satisfaction. The habit of customers was found to be negatively correlated with satisfaction during the pandemic period. The study findings thus show that Thai consumers are willing to adopt a food delivery app if they gain a pleasant experience when using it. Consequently, food delivery service app operators should seek to maintain and improve user satisfaction as this is imperative for achieving success in the food delivery business, especially during the current pandemic. This finding also suggests that academics and practitioners should further refine and implement the existing model of technology acceptance.

\section{Study Limitations and Future Research Direction}

This study had some limitations. First, it was confined to the context of Thailand and was limited to Thai consumers. Second, the study's results cannot be generalized even across different areas in Thailand as they were obtained through nonprobability sampling. Thus, the study's empirical findings cannot confirm the factors that will influence customer intention to use a food delivery app in the post-COVID-19-pandemic scenario as Thai customers seem to have already adapted to both the old and new normal, making the postpandemic situation unpredictable. Moreover, food delivery apps are still developing and are periodically launching new features. Hence, longitudinal research is needed in the future to refine the results of this study and to achieve better results. Finally, there is a gap in the explanatory power of this research. Therefore, other variables or antecedent variables should be incorporated in the model to better understand customer satisfaction and food delivery app adoption intention. Hence, future studies should re-examine the proposed model across cultural backgrounds, particularly in countries where food delivery apps are most used, which can help provide additional insight into the matter $[9,14,25,60]$. 
In addition, exploring customers who ignore or have rejected the use of food delivery apps will help in understanding such apps' weaknesses, which can help establish a successful food delivery app model. The unique features of food delivery apps should be included in the future model to fully capture the food delivery app context [12], which will provide better insights into the unique factors influencing customer satisfaction and user intention in such context.

Author Contributions: Conceptualization, J.C.; data curation, J.C.; formal analysis, J.C.; funding acquisition, J.C.; investigation, J.C.; methodology, J.C.; project administration, J.C.; software, J.C.; writing —original draft, J.C.; writing—review and editing, J.C. and Y.K. All authors have read and agreed to the published version of the manuscript.

Funding: This research was partially supported by grants-in-aid for scientific research from the Japan Society for the Promotion of Science (JSPS C:21K01734).

Institutional Review Board Statement: Not applicable.

Informed Consent Statement: Not applicable.

Conflicts of Interest: The authors declare no conflict of interest.

\section{Appendix A}

Table A1. Measurement Items.

\begin{tabular}{|c|c|}
\hline Items & Measurement Indexes \\
\hline PV1 & Food delivery apps offer a reasonable price. \\
\hline PV2 & Using a food delivery app service is good value for money. \\
\hline PV3 & At current prices, the food delivery app provides a good price. \\
\hline SI1 & $\begin{array}{l}\text { People who are important to me think that I should use a food delivery app for } \\
\text { ordering food. }\end{array}$ \\
\hline SI2 & $\begin{array}{l}\text { People around me are in favor of using food delivery apps, so when I would like to } \\
\text { order the food, I use a food delivery app. }\end{array}$ \\
\hline SI3 & $\begin{array}{l}\text { Social networks, advertising, comments and reviews, and word of mouth influence } \\
\text { me on whether or not to using food delivery apps. }\end{array}$ \\
\hline HT1 & Using food delivery apps has become a habit for me. \\
\hline HT2 & I am addicted to using food delivery apps to order food. \\
\hline HT3 & I feel the need to use food delivery apps in my daily life. \\
\hline $\mathrm{T} 1$ & Food delivery apps are trustworthy. \\
\hline $\mathrm{T} 2$ & A food delivery app is a reliable means of carrying out transactions. \\
\hline T3 & $\begin{array}{l}\text { I think food delivery apps are truthful in their dealings, with high integrity, and they } \\
\text { keep my best interest in mind. }\end{array}$ \\
\hline $\mathrm{C} 1$ & Using food delivery apps enables me to purchase food at any time I want. \\
\hline $\mathrm{C} 2$ & Using a food delivery app enables me to purchase food wherever I am. \\
\hline $\mathrm{C} 3$ & I find that food delivery apps are convenient for purchasing food. \\
\hline AQ1 & Food delivery apps are easy to use. \\
\hline AQ2 & $\begin{array}{l}\text { Food delivery apps allow me to search and locate the information I need quickly } \\
\text { and effectively. }\end{array}$ \\
\hline AQ3 & The information provided by food delivery apps is accurate and reliable. \\
\hline $\mathrm{AQ} 4$ & The information provided by food delivery apps is understandable and clear. \\
\hline AQ5 & $\begin{array}{l}\text { Food delivery app staff show a sincere interest in solving and troubleshooting } \\
\text { technical problems and normally provide quality service. }\end{array}$ \\
\hline AQ6 & $\begin{array}{l}\text { Food delivery staff provide undivided attention whenever I experience a problem } \\
\text { and dedicate enough time to resolving my specific technical needs and concerns. }\end{array}$ \\
\hline Sa1 & I am delighted to order food via food delivery apps. \\
\hline $\mathrm{Sa} 2$ & The service provided by food delivery apps meets or exceeds my expectations. \\
\hline $\mathrm{Sa} 3$ & I think I made the right decision in using food delivery apps to order food \\
\hline I1 & I intend to continue using food delivery apps. \\
\hline $\mathrm{I} 2$ & I would recommend using a food delivery app to family, colleagues, and friends. \\
\hline I3 & I intend to increase my use of food delivery apps when the opportunity arises. \\
\hline
\end{tabular}




\section{References}

1. Apornrath, P. Thai Fast-Food Chain Operator to Open 100 'Cloud Kitchens' by 2024. NIKKEI Asia. 14 July 2020. Available online: https:/ / asia.nikkei.com/Business/Food-Beverage/Thai-fast-food-chain-operator-to-open-100-cloud-kitchens-by-2024 (accessed on 18 November 2020).

2. Kresearch. Food Delivery Application Pushes Continuous Growth in the Food Delivery Business. 22 May 2019. Available online: https: / /www.kasikornresearch.com/th/analysis/k-econ/business/Pages/z2995.aspx?fbclid=IwAR2KHbKGS0Fi4Bc6 uIEMyeTrLOjg2d9p80YDA7c1KzNKUImsB0qM24Wf3M (accessed on 15 June 2020).

3. Kadono, Y. Management of Software Engineering Innovation in Japan, 1st ed.; Springer: Tokyo, Japan, 2015.

4. Laura, L.; Clayton, O.; Jeremy, S.; Kate, S. How COVID-19 Has Pushed Companies over the Technology Tipping Point and Transformed Business Forever. McKinsey \& Company. 5 October 2020. Available online: https://www.mckinsey.com/businessfunctions / strategy-and-corporate-finance/our-insights/how-covid-19-has-pushed-companies-over-the-technology-tippingpoint-and-transformed-business-forever (accessed on 22 January 2021).

5. ETDA. Thai People Spend the Average of 10 Hours 22 Minutes Per Day Using the Internet. 22 May 2020. Available online: https: / www.etda.or.th/th/NEWS/ETDA-Revealed-Thailand-Internet-User-Behavior-2019.aspx (accessed on 22 January 2021).

6. Fitch, S. Thai Food Delivery Market Taking Off. Bangkok Post. 13 November 2020. Available online: https://www.bangkokpost. com/business / 2019015/thai-food-delivery-market-taking-off (accessed on 17 December 2020).

7. Yorlin, N. Food Delivery in South East Asia Grew 183\% in 2020, Accelerated by COVID-19, According to Momentum Works. 12 January 2021. Available online: https:/ / thelowdown.momentum.asia/press-release-food-delivery-in-south-east-asia-grew183-in-2020-accelerated-by-covid-19-according-to-momentum-works / (accessed on 22 January 2021).

8. Sukanya, S. The Impact of the COVID-19 Outbreak on the Thai Food Retail and Food Service Sector. 22 May 2020. Available online: https:/ /apps.fas.usda.gov /newgainapi/api/Report/DownloadReportByFileName?fileName=The $\% 20 \mathrm{Impact} \% 20 \mathrm{of} \%$ 20the\%20COVID-19\%20Outbreak\%20on\%20the\%20Thai\%20Food\%20Retail\%20and\%20Food\%20Service\%20Sector_Bangkok_ Thailand_05-21-2020 (accessed on 22 November 2020).

9. Chotigo, J.; Kadono, Y. Are there any key factors that encourage food delivery application during the COVID-19 pandemic in Thailand and the role of HRM. Hum. Syst. Manag. 2021. [CrossRef]

10. Pigatto, G.; Machado, J.G.d.C.F.; Negrett, A.d.S.; Machado, L.M. Have you chosen your request? Analysis of online food delivery companies in Brazil. Br. Food J. 2017, 119, 639-657. [CrossRef]

11. Kapoor, A.P.; Vij, M. Technology at the dinner table: Ordering food online through mobile apps. J. Retail. Consum. Serv. 2018, 43, 342-351. [CrossRef]

12. Roh, M.; Park, K. Adoption of $\mathrm{O} 2 \mathrm{O}$ food delivery services in South Korea: The moderating role of moral obligation in meal preparation. Int. J. Inf. Manag. 2019, 47, 262-273. [CrossRef]

13. Cho, M.; Bonn, M.A.; Li, J.J. Differences in perceptions about food delivery apps between single-person and multi-person households. Int. J. Hosp. Manag. 2018, 77, 108-116. [CrossRef]

14. Alalwan, A.A. Mobile food ordering apps: An empirical study of the factors affecting customer e-satisfaction and continued intention to reuse. Int. J. Inf. Manag. 2020, 50, 28-44. [CrossRef]

15. Okumus, B.; Ali, F.; Bilgihan, A.; Ozturk, A.B. Psychological factors influencing customers' acceptance of smartphone diet apps when ordering food at restaurants. Int. J. Hosp. Manag. 2018, 72, 67-77. [CrossRef]

16. Maciejewski, G. Consumers towards Sustainable Food Consumption. Mark. Sci. Res. Organ. 2020, 36, 19-30. [CrossRef]

17. Vincent, V.V. Bangkok's Coronavirus Lockdown Fuelled Food-Delivery Wars. Will Players Survive? This Week in ASIA. 28 June 2020. Available online: https:/ / www.scmp.com/week-asia/lifestyle-culture/article/3090795/bangkoks-coronavirus-lockdownfuelled-food-delivery (accessed on 18 November 2020).

18. Econ. Food Delivery Business Booms Amid Covid-19 Outbreak. The Nation Thailand. 10 August 2020. Available online: https: / / www.nationthailand.com/business /30392754?utm_source=homepage\&utm_medium=internal_referral (accessed on 18 November 2020).

19. Al-Maroof, R.A.S.; Al-Emran, M. Students Acceptance of Google Classroom: An Exploratory Study using PLS-SEM Approach. Int. J. Emerg. Technol. Learn. 2018, 13, 112-123. [CrossRef]

20. Dutot, V. Factors influencing Near Field Communication (NFC) adoption: An extended TAM approach. J. High Technol. Manag. Res. 2015, 26, 45-57. [CrossRef]

21. Chi, T. Mobile Commerce Website Success: Antecedents of Consumer Satisfaction and Purchase Intention. J. Internet Commer. 2018, 17, 189-215. [CrossRef]

22. Macedo, I.M. Predicting the acceptance and use of information and communication technology by older adults: An empirical examination of the revised UTAUT2. Comput. Hum. Behav. 2017, 75, 935-948. [CrossRef]

23. Merhi, M.; Hone, K.; Tarhini, A. A cross-cultural study of the intention to use mobile banking between Lebanese and British consumers: Extending UTAUT2 with security, privacy and trust. Technol. Soc. 2019, 59, 101151. [CrossRef]

24. Shaw, N.; Sergueeva, K. The non-monetary benefits of mobile commerce: Extending UTAUT2 with perceived value. Int. J. Inf. Manag. 2019, 45, 44-55. [CrossRef]

25. Alalwan, A.A.; Dwivedi, Y.K.; Rana, N.P. Factors influencing adoption of mobile banking by Jordanian bank customers: Extending UTAUT2 with trust. Int. J. Inf. Manag. 2017, 37, 99-110. [CrossRef] 
26. Alalwan, A.A.; Dwivedi, Y.K.; Rana, N.P.; Algharabat, R. Examining factors influencing Jordanian customers' intentions and adoption of internet banking: Extending UTAUT2 with risk. J. Retail. Consum. Serv. 2018, 40, 125-138. [CrossRef]

27. Zhao, Q.; Chen, C.-D.; Wang, J.-L. The effects of psychological ownership and TAM on social media loyalty: An integrated model. Telemat. Inform. 2016, 33, 959-972. [CrossRef]

28. Weli, W. Student Satisfaction and Continuance Model of Enterprise Resource Planning (ERP) System Usage. Int. J. Emerg. Technol. Learn. 2019, 14, 71-83. [CrossRef]

29. Escobar-Rodríguez, T.; Carvajal-Trujillo, E. Online purchasing tickets for low cost carriers: An application of the unified theory of acceptance and use of technology (UTAUT) model. Tour. Manag. 2014, 43, 70-88. [CrossRef]

30. Wang, Y.-S.; Tseng, T.H.; Wang, W.-T.; Shih, Y.-W.; Chan, P.-Y. Developing and validating a mobile catering app success model. Int. J. Hosp. Manag. 2018, 7, 19-30. [CrossRef]

31. Venkatesh, V.; Thong, J.Y.L.; Xu, X. Consumer acceptance and use of information technology: Extending the unified theory of acceptance and use of technology. MIS Q. 2012, 36, 157-178. [CrossRef]

32. Srivastava, M.; Kaul, D. Social interaction, convenience, and customer satisfaction: The mediating effect of customer experience. J. Retail. Consum. Serv. 2014, 21, 1028-1037. [CrossRef]

33. Chen, C.C.; Hsiao, K.L.; Hsieh, C.H. Understanding usage transfer behavior of two way O2O services. Comput. Hum. Behav. 2019, 100, 184-191. [CrossRef]

34. Jenny, O.; Bahtiar, S.A. Measuring Students Satisfaction in Using Learning Management System. Int. J. Emerg. Technol. Learn. 2019, 14, 180-189.

35. Iyer, P.; Davari, A.; Mukherjee, A. Investigating the effectiveness of retailers' mobile applications in determining customer satisfaction and repatronage intentions? A congruency perspective. J. Retail. Consum. Serv. 2018, 44, 235-243. [CrossRef]

36. Venkatesh, V.; Morris, M.G.; Davis, G.B.; Davis, F.D. User Acceptance of Information Technology: Toward a Unified View. MIS Q. 2003, 27, 425-478. [CrossRef]

37. Morosan, C.; DeFranco, A. It's about time: Revisiting UTAUT2 to examine consumers' intentions to use NFC mobile payments in hotels. Int. J. Hosp. Manag. 2016, 53, 17-29. [CrossRef]

38. Hsiao, C.-H.; Chang, J.-J.; Tang, K.-Y. Exploring the influential factors in continuance usage of mobile social Apps: Satisfaction, habit, and customer value perspectives. Telemat. Inform. 2016, 33, 342-355. [CrossRef]

39. Gallarza, M.G.; Gil Saura, I. Value dimensions, perceived value, satisfaction and loyalty: An investigation of university students travel behaviour. Tour. Manag. 2006, 27, 437-452. [CrossRef]

40. Limayem, M.; Hirt, S.G. Force of habit and information systems usage: Theory and initial validation. J. Assoc. Inf. Syst. 2003, 4, 65-97. [CrossRef]

41. Chae, H.; Kim, S.; Lee, J.; Park, K. Impact of product characteristics of limited edition shoes on perceived value, brand trust, and purchase intention; focused on the scarcity message frequency. J. Bus. Res. 2020, 120, 398-406. [CrossRef]

42. Wu, H.C.; Cheng, C.C.; Ai, C.H. A study of experiential quality, experiential value, trust, corporate reputation, experiential satisfaction, and behavioral intentions for cruise tourists: The case of Hong Kong. Tour. Manag. 2018, 66, 200-220. [CrossRef]

43. Zhao, J.-D.; Huang, J.-S.; Su, S. The effects of trust on consumers' continuous purchase intentions in C2C social commerce: A trust transfer perspective. J. Retail. Consum. Serv. 2019, 50, 42-49. [CrossRef]

44. Jiang, C.; Rashid, R.M.; Wang, J. Investigating the role of social presence dimensions and information support on consumers trust and shopping intentions. J. Retail. Consum. Serv. 2019, 51, 263-270. [CrossRef]

45. Zhou, T. Examining the critical success factors of mobile website adoption. Online Inf. Rev. 2011, 35, 636-652. [CrossRef]

46. Kim, D.J.; Ferrin, D.L.; Rao, H.R. Trust and Satisfaction, Two Stepping Stones for Successful E-Commerce Relationships: A Longitudinal Exploration. Inf. Syst. Res. 2009, 20, 237-257. [CrossRef]

47. Hsu, M.-H.; Chang, C.M.; Chu, K.K.; Lee, Y.J. Determinants of repurchase intention in online group-buying: The perspectives of DeLone \& McLean IS success model and trust. Comput. Hum. Behav. 2014, 36, 234-245.

48. Li, B.; Wu, Y.; Hao, Z.; Yan, X.; Chen, B. The effects of trust on life satisfaction in the context of WeChat use. Telemat. Inform. 2019, 42, 101241. [CrossRef]

49. Copeland, M.T. Relation of consumers' buying habits to marketing methods. Harv. Bus. Rev. 1923, 1, $282-289$.

50. Duarte, P.; Costa e Silva, S.; Ferreira, M.B. How convenient is it? Delivering online shopping convenience to enhance customer satisfaction and encourage e-WOM. J. Retail. Consum. Serv. 2018, 44, 161-169. [CrossRef]

51. Kang, A.S.; Jayaraman, K.; Soh, K.-L.; Wong, W.P. Convenience, flexible service, and commute impedance as the predictors of drivers' intention to switch and behavioral readiness to use public transport. Transp. Res. Part F Traffic Psychol. Behav. 2019, 62, 505-519. [CrossRef]

52. Shankar, A.; Rishi, B. Convenience matter in mobile banking adoption intention? Australas. Mark. J. 2020, 28, 273-285. [CrossRef]

53. DeLone, W.; McLean, E. The DeLone and McLean model of information systems success: A ten-year update. J. Manag. Inf. Syst. 2003, 19, 9-30.

54. Wang, C.; Teo, T.S.H. Online service quality and perceived value in mobile government success: An empirical study of mobile police in China. Int. J. Inf. Manag. 2020, 52, 102076. [CrossRef]

55. Wang, Q.; Kim, Y.; Roh, T. Do information and service quality affect perceived privacy protection, satisfaction, and loyalty? Evidence from a Chinese O2O-based mobile shopping application. Telemat. Inform. 2020, 56, 101483. 
56. Hwang, S.; Kim, S. Does my experience affect satisfaction with and loyalty toward O2O services? Comput. Hum. Behav. 2018, 82, 70-80. [CrossRef]

57. Davis, F.D. Perceived usefulness, perceived ease of use, and user acceptance of information technology. Manag. Inf. Syst. Q. 1989, 13, 319-340. [CrossRef]

58. Lee, S.W.; Sung, H.J.; Jeon, H.M. Determinants of Continuous Intention on Food Delivery Apps: Extending UTAUT2 with Information Quality. Sustainability 2019, 11, 3141. [CrossRef]

59. Palau-Saumell, R.; Forgas-Coll, S.; Sánchez-García, J.; Robres, E. User Acceptance of Mobile Apps for Restaurants: An Expanded and Extended UTAUT-2. Sustainability 2019, 11, 1210. [CrossRef]

60. Oliveira, T.; Thomas, M.; Baptista, G.; Campos, F. Mobile payment: Understanding the determinants of customer adoption and intention to recommend the technology. Comput. Hum. Behav. 2016, 61, 404-414. [CrossRef]

61. Verkijika, S.F. Factors influencing the adoption of mobile commerce applications in Cameroon. Telemat. Inform. 2018, 35, 1665-1674. [CrossRef]

62. Escobar-Rodríguez, T.; Carvajal-Trujillo, E. Online drivers of consumer purchase of website airline tickets. J. Air Transp. Manag. 2013, 32, 58-64. [CrossRef]

63. Nunnally, J.C. Psychometric Theory, 2nd ed.; McGraw-Hill: New York, NY, USA, 1978.

64. Kline, R.B. Principles and Practice of Structural Equation Modelling; The Guilford Press: New York, NY, USA, 2005.

65. Evans, J.R.; Mathur, A. The value of online surveys. Internet Res. 2005, 15, 195-219.

66. Liu, F.; Zhao, X.; Chau, P.; Tang, Q. Roles of perceived value and individual differences in the acceptance of mobile coupon applications. Internet Res. 2015, 25, 471-495. [CrossRef]

67. Mutaz, M.A.; Dima, J.; Enas, A. Measuring web portals success: A re-specification and validation of the DeLone and McLean information systems success model. Int. J. Bus. Inf. Syst. 2013, 14, 96-133.

68. Xiao, L.; Mi, C.; Zhang, Y.; Ma, J. Examining Consumers' Behavioral Intention in O2O Commerce from a Relational Perspective: An Exploratory Study. Inf. Syst. Front. 2017, 21, 1045-1068. [CrossRef]

69. Ashfaq, M.; Yun, J.; Waheed, A.; Khan, M.S.; Farrukh, M. Customers' Expectation, Satisfaction, and Repurchase Intention of Used Products Online: Empirical Evidence from China. Sage Open 2019, 9, 215824401984621. [CrossRef]

70. Hair, J.; Black, W.C.; Babin, B.J.; Anderson, R.E. Multivariate Data Analysis, 7th ed.; Pearson Educational International: Upper Saddle River, NJ, USA, 2010.

71. Bollen, K.A. A New Incremental Fit Index for General Structural Equation Models. Sociol. Methods Res. 1989, 17, 303-316. [CrossRef]

72. Ryu, M.H.; Kim, J.; Kim, S. Factors affecting application developers' loyalty to mobile platforms. Comput. Hum. Behav. 2014, 40, 78-85. [CrossRef]

73. Bagozzi, R.P.; Yi, Y.; Phillips, L.W. Assessing construct validity in organizational research. Adm. Sci. Q. 1991, 36, 421-458. [CrossRef]

74. Statista. Smartphone Penetration Rate as Share of the Population in Thailand from 2017 to 2019 and a Forecast for 2020 through 2025. 2 September 2020. Available online: https:/ /www.statista.com/statistics/625455/smartphone-user-penetrationin-thailand/ (accessed on 19 November 2020). 